\title{
Testing Financial Contagion in Emerging Countries: Evidence From BRICS Countries
}

\author{
Olivier Niyitegeka ${ }^{1}$ \\ ${ }^{1}$ Regent Business School, Durban, South Africa \\ Correspondence: Dr. Olivier Niyitegeka, 35 Samora Machel Street, Durban, South Africa. E-mail: \\ oliniyitegeka@gmail.com; olivier.niyitegeka@regent.ac.za \\ Received: January 13, 2022 \\ Accepted: February 7, $2022 \quad$ Online Published: February 10, 2022 \\ doi:10.5430/ijfr.v13n1p42 \\ URL: https://doi.org/10.5430/ijfr.v13n1p42
}

\begin{abstract}
This study uses a Multivariate Generalised Autoregressive Conditional Heteroskedasticity (MGARCH) model to examine the pure form of financial contagion in BRICS countries (Brazil, Russia, India, China, and South Africa) in the wake of two major international financial crises namely the U.S. sub-prime and Eurozone sovereign debt crises (EZDC). The pure form of contagion refers to the spread of shocks that are unrelated to macroeconomic fundamentals and are simply the product of irrational phenomena like panics, herd behaviour, loss of confidence, and risk aversion. To investigate contagion the present study analyses the pairwise dynamic cross-correlation between the US and Eurozone equity markets as 'source' (ground zero) markets and individual BRICS stock markets as 'target' markets.

For the each of the two crises that are examined the sets of data used, were divided into two sub-periods (1) the crisis period and (2) the stable period. For the Sub-prime crisis, the findings of the present study indicate the presence of cross-conditional volatility between the US and BRICS stock markets. The results also showed that the cross-conditional volatility coefficient is high in magnitude during periods of financial upheaval compared to a tranquil period, hence the conclusion that there was financial contagion during in BRICs stock markets (except in Chinese market) following the U.S. sub-prime crisis. As for the EZDC, equity markets in Brazil, India and China seemed to react equally (in both the 'crisis' and 'post-crisis' periods) from shocks emanating from European equity market. Hence the conclusion that there was no contagion in Brazil, India and China following the Eurozone sovereign debt crisis.
\end{abstract}

Keywords: financial contagion, emerging markets, BRICS, diagonal VECH GARCH, sub-prime crisis, Eurozone sovereign debt crises

\section{Introduction}

The most prevalent features of emerging economies, include among others, a steady increase in GDP and GDP per capita, an increase in foreign trade exceeding that of international trade, the presence of foreign capital invested over the long-term, a diversified economy, a promising economic prospect, and political stability. However, there are no set criteria for determining whether or not a country qualifies to be an emerging country (O’Neil, 2021). Strictly on economic standpoint, divergences, structural characteristics and vulnerability, particularly to capital flows, can vary widely across emerging economies making it difficult to categorise them (Duttagupta \& Pazarbasioglu,2021). For these reasons classifying emerging countries as a block - such as advanced countries block, the dollar block or the European block - has often proved to be a daunting task. There have been attempts to classify emerging countries into various of sub-groups, sometimes with well-known acronyms such as BEM, BENIVM, BNP, BRICK, BRICM, BRICS, BRICS+, BRICSAM, BRIICSSAMT, CIVETS, E7, EAGLES, MANGANESE, MINT, MIST, NEST, PPICS, TIMBI, VISTA among others. These classifications, however, have been in most instances unsatisfactory (Ithurbide \& Bellaich, 2019). The only strong factor that justifies the existence of an emerging block, is the fact that the emerging world tends to behave like a block when the global financial conditions deteriorate sharply, and risk aversion becomes high. According to Ithurbide and Bellaich (2019) this is because there are no safe havens or reserve currencies in the emerging world, the authors maintained that any common global factor (such as a surprise announcement by the reserve bank to raise rates, a sharp reversal in capital inflows, or the fear of a trade war) causes financial contagion, which affects emerging markets almost uniformly. 
The BRICS acronym is one of the well-known acronyms used to categorise emerging markets, it has come to be seen as a symbol as a symbol of the shift in global economic power away from the developed economies - like the U.S.toward the developing world (Koba,2011). The acronym was coined by O'Neil (2001), in a World Bank publication titled "Building Better Global Economic BRICs". BRIC pertained to the original four countries - Brazil, Russia, India, and China. Because of their large size, population, desire to become the world's leading economies, and motivated by their extraordinary rise, BRIC countries were the rising stars of emerging markets. South Africa joined the group as a full member at the 2011 Sanya Summit, in China. The group was therefore renamed BRICS, to reflect the expanded membership of the group. More than two decades after O'Neil's publication, the aspirations of the BRICS countries as the world's leading emerging-market economies remain today and for the future as the global economy's development engines (Bonga-Bonga, 2018). Wilson and Purushothaman (2003) projected that the BRIC (without South Africa) economies would become a much stronger force in the global economy by year 2050 (Note $1)$.

The following are the most prevalent features of BRICS economies: (i) a significant economic growth that averages $5 \%$ for the long-run, (ii) strong demographic indicators characterised by a young and educated population, combined with notable demographic growth (studies have shown that having 100 million inhabitants is a minimum in order to constitute a sizeable domestic market), (iii) a diversified economy that does not relying only on the export of raw materials, meaning that sectors such as industry and services are well developed, and finally, (iv) political stability where political institutions are stable enough to allow the implementation of long-term policies.

The current study examines financial contagion in BRICS market, the choice of these emerging countries was motivated by the fact that they have stronger partnerships through the BRICS association. Additionally, these countries come from various continents across the world. This allowed the researcher to have a worldwide overview of how the contagions are transmitted, not only in one region but across regions. The study uses a MGARCH model as a measure of financial contagion. Identifying these feature byways of multivariate modelling results in more insightful analysis than operating with separate univariate models. From a financial perspective, it paves the way to better decision-making tools in different fields, such as asset pricing, portfolio selection, option pricing, hedging, and risk management.

The rest of this article is structured as follows. Section two reviews the literature on financial contagion in emerging markets, Section three presents the time series data used in the current study, covering descriptive statistics and preliminary analysis of data. The section also discusses the main empirical models and the estimation methodology used. The empirical results obtained from the analysis are presented in Section four. Section five concludes with a summary and Section six provides policy recommendations.

\section{Literature Review}

Financial contagion can be defined as a significant increase in cross-market linkages after a shock. Although drawing analogies between the propagation of the financial crisis and the spread of medical disease might seem fanciful, the two are similar on several levels as they both refer to the transmission of a malady through direct or indirect contact. According to Cheung, Tam and Szeto (2009), a metaphorical definition of contagion, as "the spreading of a harmful idea or theory", is also applicable to the spread of a financial crisis. They pointed out that some financial contagions, like the Russia virus that occurred in 1998, were based on changes in investor "psychology," "attitude," and "behaviour", for various reasons. For instance, less-informed investors might opt to discard their information and instead decide to follow the "leader" blindly, causing markets to move together. Despite the surge of interest in contagion after the series of crises in the 1990s, many of the critical questions remain unanswered on the correct definition of contagion. There have been disagreements as to whether the term contagion should apply between two countries that have similar macroeconomic fundamentals and are closely linked. The U.S. and Canada, for example, are in the same geographic area and have many similarities in terms of market structure and history. The U.S. and Canada are always linked during stable and crisis periods. The propagation of a significant scare during a period of crisis is just a continuation of the interdependence that exists during tranquil periods. Nevertheless, there are mixed views concerning whether the propagation of a crisis that occurred between Brazil and Argentina at the beginning of 1999 was a contagion. On 13 January 1999, the Brazilian stock market fell by 13 per cent, and the Argentine stock market declined by 9 per cent. This propagation was an example of financial contagion. The following day the Brazilian market recovered by 23 per cent and the Argentine market rose by 11 per cent. However, during that period of crisis Argentina had relatively stable fiscal and current account balances and the spillover onto Argentina's economy was unwarranted, given Argentina's strong economic fundamentals (Forbes and Rigobon, 2002). Most academics agree that when two economies are located in a separate geographic area and have weak macroeconomic 
fundamentals, nor have direct linkages (such as financial trade) the propagation of crisis from one country to another is undoubtedly contagion. This is also the case of the contagion that occurred between Russia and Brazil towards the end of 1998.

Claessens and Forbes (2004) propose a more inclusive definition of contagion. It captures the vulnerability of one country to events happening in other countries. The vulnerability exists regardless of the cause, or whether or not there are links between the countries concerned. However, as the authors argue, it is useful to distinguish between a broader definition of contagion and shift contagion to allow policymakers and government officials to assess the effectiveness of the intervention and financial assistance packages needed during the financial crisis.

An extensive literature on financial contagion in emerging markets has developed in the aftermath of the global financial crisis of 2008-2009 and the Eurozone crisis of 2009-2012. These include, among others Ahmad, Sehgal and Bhanumurthy (2013) who investigated the contagion effects of Greece, Ireland, Portugal, Spain, Italy, USA, UK and Japan markets on BRIICKS (Brazil, Russia, India, Indonesia, China, South Korea and South Africa) stock markets, during the Euro-zone crisis period, and their empirical results indicated that among Eurozone countries, Ireland, Italy and Spain appeared to be most contagious for BRIICKS markets compared to Greece. The study also indicated that the contagious shock strongly hit Brazil, India, Russia, China and South Africa during the Eurozone crisis. However, Ahmad, Sehgal and Bhanumurthy (2013) found that Indonesia and South Korea experienced only interdependence and not contagion. Kenourgios and Dimitriou (2015) examined the contagion effects of the global financial crisis of 2008 and 2009 in ten sectors within six developed and emerging regions during different phases of the crisis. Their findings indicated that the global financial crisis of 2008-2009 can be characterised by contagion effects across regional stock markets and regional financial and non-financial sectors. However, they noted that developed countries in the Pacific region, and some sectors (in particular consumer goods, healthcare and technology) across all regions, were less affected by the crisis, while the most vulnerable sectors were observed in the emerging Asian and European regions. Hemche, Jawadi, Maliki and Cheffou (2016) studied the contagion hypothesis for ten developed and emerging stock markets (namely France, Italy, UK, Japan, China, Argentina, Mexico, Tunisia, Morocco and Egypt) concerning the U.S. market in the context of the sub-prime crisis. Their findings indicated that there was an increase in dynamic correlations following the sub-prime crisis for most markets under consideration with respect to the U.S. market. Aizenman, Jinjarak, Lee and Park (2016) used the event study methodology to measure the scope for financial contagion from the EU to developing countries. They showed that, although global crisis news had a consistent negative impact on developing country equities and bond market returns, the impact of crisis news was more mixed and limited. Mohti, Dionísio, Vieira and Ferreira (2019) examine the effects of the US financial and the Eurozone debt crises on a large set of frontier stock markets using Detrended Cross Correlation Analysis (DCCA) and Detrended Moving Cross Correlation Analysis (DMCA), their results showed that frontier markets were affected by both crises DCCA and DMCA coefficients increased significantly for countries in Europe and also, although not so strongly, for Middle Eastern ones with the subprime crisis. Regarding the Eurozone debt crisis, the authors showed that the most affected countries were the showed that Slovenia, Romania, Nigeria, Kuwait, Oman and Vietnam. Niyitegeka and Tewari (2021) used the Dynamic Conditional Correlation (DCC)-GARCH model to investigate financial contagion in the wake of the Sub-prime and EuroZone Sovereign Debt Crises .For the Sub-prime crisis they found evidence of cross-conditional volatility between the US and BRICS stock markets. The results also showed that the cross-conditional volatility coefficient is high in magnitude during periods of financial upheaval compared to a tranquil period, hence the conclusion that there was financial contagion in BRIC stock markets (except in Chinese market) following the U.S. sub-prime crisis. Niyitegeka and Tewari (2021) could not find evidence of contagion in BRICS equity market emanating the Eurozone market except for South African and the Russian stock market.

\section{Data and Methodology}

This section describes the data and econometric models used to investigate financial contagion in BRICS stock market following the sub-prime crisis which emanated from the U.S and the EZDC that emanated from Eurozone countries. The econometric model is the Diagonal VECH GARCH.

\subsection{Data}

The present study analyses the pairwise dynamic cross-correlation between the US and Eurozone equity markets as source (ground zero) markets and individual BRICS stock markets as target markets. The data used comprise daily closing stock price of indices from individual BRICS countries, Germany and the United States. The data spans a period between 11th of January 2005 and 26th of December 2017 (providing 2443 daily observations for each market). The 'target' stock market indices examined are those in the Brazilian BOVESPA (São Paulo Stock 
Exchange/Bolsa de Valores de São Paulo index), the Chinese SSE (Shanghai Stock Exchange index,), the Indian SENSEX (Bombay Stock exchange index), the Russian RTS (Moscow Exchange index) and the South African FTSE/JSE All share (Johannesburg Stock Exchange index, hereafter referred as FTSE/JSE). For 'source' markets the daily stock price index of the United States, the S\&P 500, and the German, DAX Composite index is used as the proxy for the Eurozone (continental Europe) stock market. The study used daily data to get meaningful statistical generalisation and obtain a clearer picture of the movement of market returns. A potential drawback is the effectiveness of daily data due to trading hour differences, but, as Forbes and Rigobon (2002) stressed, this represents a relative problem as attempts to circumvent the problem by using the average returns failed to find a meaningful difference in their results.

Figures 1 displays the time series plot of indices used in the current study. The time series is non-stationary due to the non-constant mean.

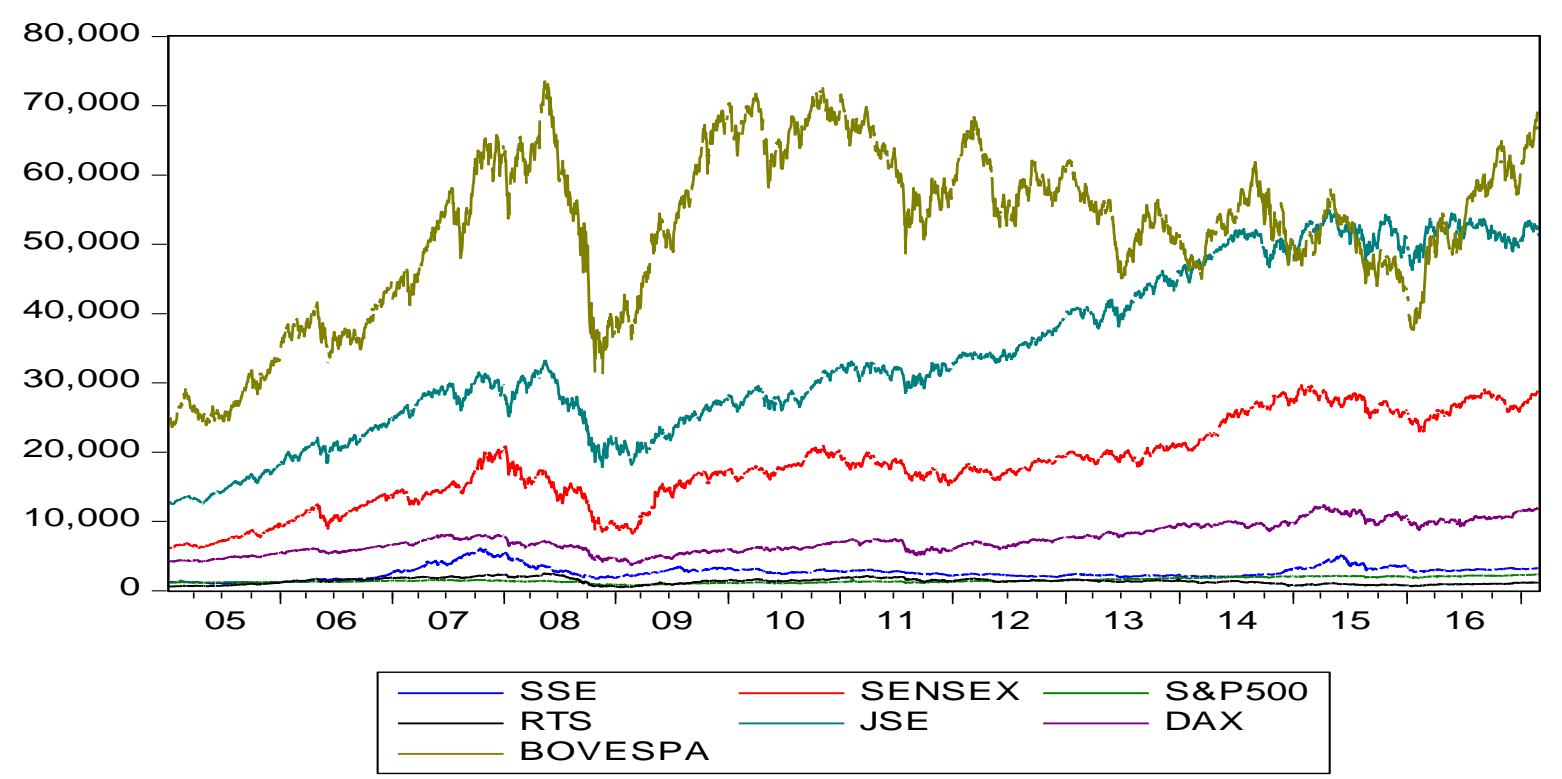

Figure 1. Daily Stock Market Indices of BRICS Countries, Germany and the U.S

For detrending, and in order to achieve more stationary time series data, the daily price indices were transformed into natural logarithmic returns expressed as follows:

$$
R_{t}=\left[\ln \left(P_{t}\right)-\ln \left(P_{t-1}\right)\right] \times 100
$$

where $P_{t}$ is the closing price index recorded for period $\mathrm{t}$, and $P_{t-1}$ is the closing price index recorded for period $\mathrm{t}$-1.The reason for multiplying the expression $\ln \left(P_{t}\right)-\ln \left(P_{t-1}\right)$ by 100 is due to numerical problems in the estimation part. This will not affect the structure of the model since it is just a linear scaling.

Figures 2 to 7 illustrate the daily log returns series for price indices used in the present study. It can be seen that returns series display periods of volatility clustering, i.e. periods of high volatility are followed by periods of high volatility, and periods of low volatility are also followed by periods with the same features. The presence of volatility clustering justifies the use of GARCH models. GARCH family models have proved to be capable of capturing conditional volatility effectively (Verma, 2021). 
DAX

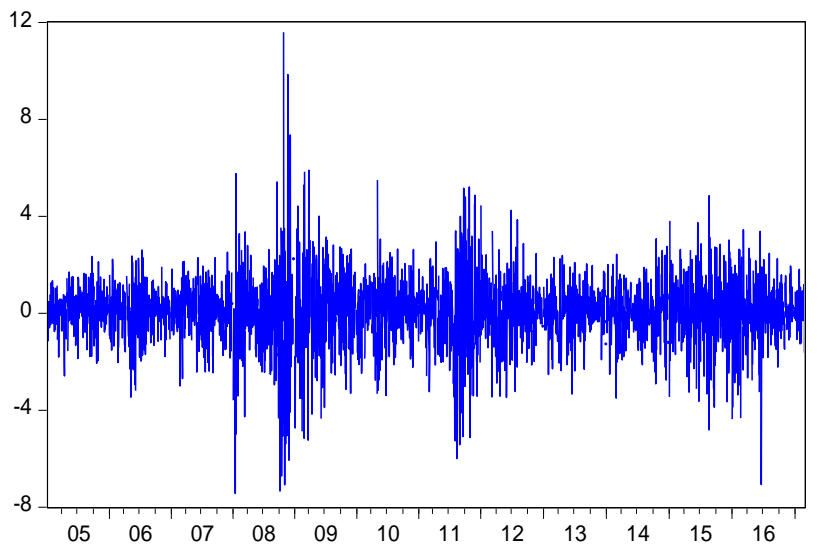

Figure 2. Daily Return Series for DAX (Europe)

RTS

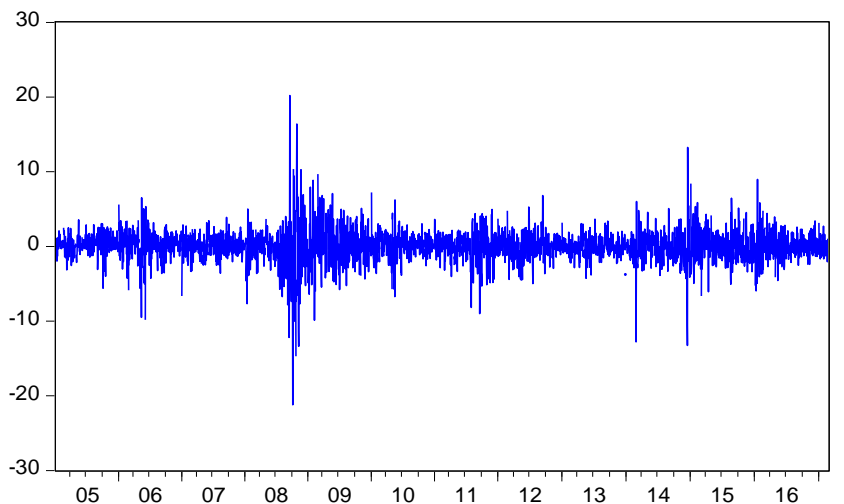

Figure 4. Daily Return Series for RTS (Russia)

S\&P500

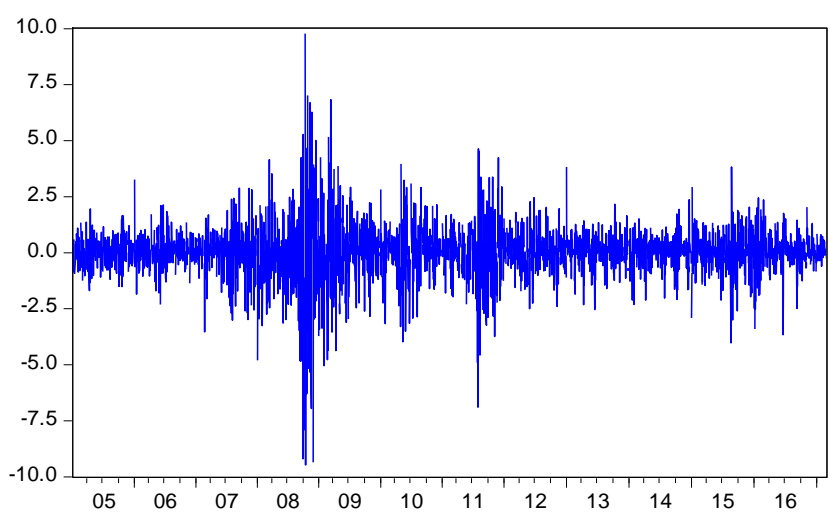

Figure 6. Daily Return Series for S\&P500 (U.S.)
JSE

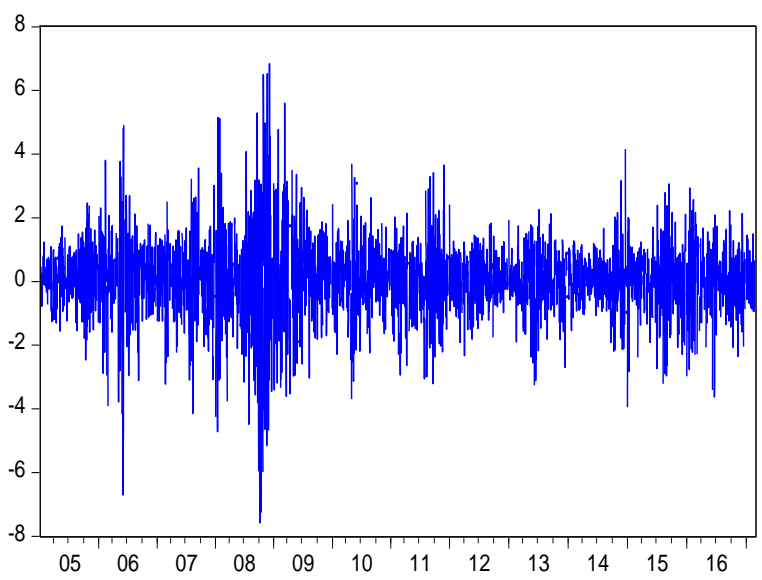

Figure 3. Daily Return Series for the FTSE/JSE All share Index (South Africa)

SSE

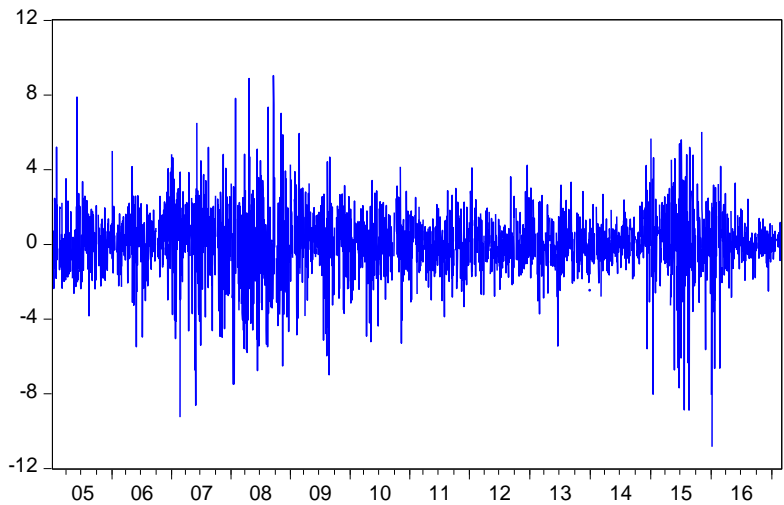

Figure 5. Daily Return Series for SSE (China)

SENSEX

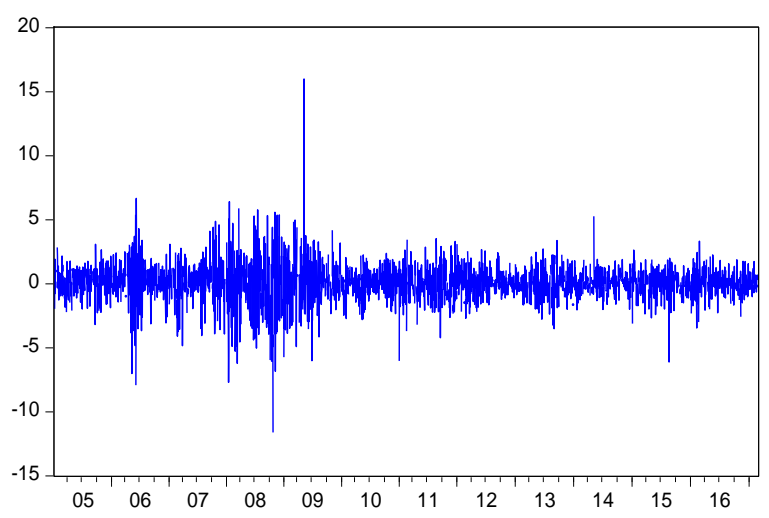

Figure 7. Daily Return Series for SENSEX(India)

In order to examine spillover volatility in BRICS equity markets following the sub-prime crisis, the present study 
uses two sub-periods, namely, the (i) 'pre-crisis'(Panel A) sub-period that ranges from $11^{\text {th }}$ February 2005 to $1^{\text {st }}$ February 2007 and (ii) the 'crisis' (Panel B) sub-period that extends from $2^{\text {nd }}$ February 2007(which corresponds to the explosion of the real estate bubble in the U.S.) to $10^{\text {th }}$ July 2009 . The study considers the S\&P 500 index as the "ground zero" host market and the volatility from the S\&P500 is construed as an exogenous shock to volatility in BRICS markets.

The summary statistics for index returns used to analyse cross volatility spillover among BRICS markets following the sub-prime crisis is presented in Table 1 . From Table 1 it can be seen that all individual equity markets recorded a lower return in the crisis period compared to the pre-crisis period. In all equity markets, with the exception of the Brazilian market, individual stock markets during the 'crisis' period have negative mean returns, whereas the return for the 'post-crisis' period is positive. It can also be seen in Table 1 that the standard deviation as a measure of volatility is high during the period of financial upheaval in the U.S. vis-à-vis the stable period. The highest volatility is recorded in the Russian equity market (3.241) during the 'crisis' period while, the lowest volatility is recorded in the South African market during the 'pre-crisis' period (1.15498).

Table 1. Summary Statistics on Market Returns During the Sub-prime Crisis

\begin{tabular}{|c|c|c|c|c|c|c|}
\hline & S\&P500 & BOVESPA & FTSE/JSE & RTS & SENSEX & SSE \\
\hline & \multicolumn{6}{|c|}{ Panel A: Pre-crisis period $11^{\text {th }}$ of January, 2005 and $1^{\text {st }}$ of February, 2007} \\
\hline Mean & 0.047466 & 0.101208 & 0.142098 & 0.223401 & 0.173346 & 0.152884 \\
\hline Median & 0.079993 & 0.159023 & 0.223531 & 0.272200 & 0.266820 & 0.118121 \\
\hline Maximum & 0.262727 & 6.149911 & 4.917269 & 6.531325 & 6.667006 & 7.890427 \\
\hline Minimum & -2.311098 & -6.559909 & -6.700281 & -9.840338 & -7.928759 & -5.482561 \\
\hline Std. Dev. & 0.195236 & 1.574503 & 1.15498 & 1.710889 & 1.420336 & 1.47509 \\
\hline Skewness & 0.195236 & -0.171090 & -0.623249 & -1.043792 & -0.718948 & 0.293580 \\
\hline Kurtosis & 4.597620 & 3.981284 & 7.687449 & 8.540531 & 7.931015 & 5.839484 \\
\hline Jarque-Bera & $\mathbf{5 3 . 5 3 3 6 5}$ & 20.74508 & 468.5582 & 743.4686 & $\mathbf{5 0 7 . 8 6 2 2}$ & 164.9958 \\
\hline p-value & 0.0000 & 0.0000 & 0.0000 & 0.0000 & 0.0000 & 0.0000 \\
\hline $\operatorname{ARCH}(2)$ & 1.931402 & 0.673702 & 10.79647 & 5.309437 & 8.161299 & 1.350170 \\
\hline p-value & 0.0541 & 0.50093 & 0.0000 & 0.000 & 0.000 & 0.1776 \\
\hline $\mathrm{Q}(24)$ & 34.065 & 29.940 & 38.554 & 39.414 & 42.093 & 34.990 \\
\hline p-value & 0.084 & 0.187 & 0.030 & 0.025 & 0.013 & 0.069 \\
\hline Qs(24) & 34.925 & 54.792 & 319.31 & 221.92 & 525.77 & 44.396 \\
\hline \multirow[t]{3}{*}{ p-value } & 0.070 & 0.0000 & 0.0000 & 0.0000 & 0.0000 & 0.007 \\
\hline & S\&P500 & BOVESPA & FTSE/JSE & RTS & SENSEX & SSE \\
\hline & \multicolumn{6}{|c|}{ Panel B: Crisis (turmoil) period: $2^{\text {nd }}$ February 2007 to $10^{\text {th }}$ July 2009} \\
\hline Mean & -0.084850 & 0.026352 & -0.038225 & -0.136935 & -0.664302 & 0.023890 \\
\hline Median & 0.065779 & 0.128736 & 0.005928 & 0.107645 & 0.074755 & 0.256313 \\
\hline Maximum & 9.774300 & 9.630997 & 6.833971 & 20.20392 & 15.98998 & 9.034458 \\
\hline Minimum & -9.469515 & -12.09607 & -7.580684 & -21.19942 & -11.60444 & -9.256085 \\
\hline Std. Dev. & 2.024399 & 2.515630 & 1.893789 & 3.241326 & 2.362209 & 2.439303 \\
\hline Skewness & -0.340646 & -0.280379 & -0.13682 & -0.224565 & 0.218631 & -0.190784 \\
\hline Kurtosis & 7.329106 & 6.043696 & 4.560280 & 11.45696 & 7.766668 & 4.424224 \\
\hline Jarque-Bera & 446.5236 & 218.3108 & 36.34445 & 1787.071 & 513.6179 & 50.09278 \\
\hline
\end{tabular}




\begin{tabular}{lllllll}
\hline p-value & 0.0000 & 0.0000 & 0.0000 & 0.0000 & 0.0000 & 0.0000 \\
\hline ARCH(3) & $\mathbf{6 . 7 5 4 9 0 2}$ & $\mathbf{4 . 8 3 6 7 4 4}$ & $\mathbf{3 . 2 9 3 1 8}$ & $\mathbf{8 . 1 5 9 2 2 2}$ & $\mathbf{1 . 1 3 3 6 3 5}$ & $\mathbf{1 . 8 7 9 4 7 8}$ \\
\hline p-value & 0.0000 & 0.000 & 0.0013 & 0.000 & 0.2576 & 0.0608 \\
\hline Q(24) & $\mathbf{6 5 . 6 8 1}$ & $\mathbf{3 4 . 0 1 4}$ & $\mathbf{5 4 . 6 0 6}$ & $\mathbf{3 9 . 4 1 4}$ & 18.998 & 22.961 \\
\hline p-value & 0.000 & 0.084 & 0.000 & 0.025 & 0.752 & 0.522 \\
\hline Qs(24) & $\mathbf{7 5 6 . 3 1}$ & $\mathbf{5 7 6 . 1 9}$ & $\mathbf{8 4 9 . 2 3}$ & $\mathbf{2 2 1 . 9 2}$ & 19.134 & $\mathbf{2 8 . 4 7 1}$ \\
\hline p-value & 0.0000 & 0.0000 & 0.0000 & 0.0000 & 0.745 & 0.0 .241 \\
\hline
\end{tabular}

Source: Estimation.

As exploratory analysis Jarque - Bera (JB) normality test was conducted, it can be seen in Table 1 that the data are not normally distributed as the JB test statistic (with the p-value reported) is significant at all levels, hence the rejection of the null hypothesis of normal distribution.

The present study also estimated the Q-statistic (and adjusted the Q-statistic) with 24 lags to test for serial correlation. The results in Table 1 show that the null hypothesis of no serial correlation and no ARCH effect is rejected. Similarly, the LM ARCH test statistics confirms the existence of autoregressive conditional heteroskedasticity $(\mathrm{ARCH})$ in all the market return and squared return series, hence justifying the use of GARCH models.

In order to analyse volatility spillover in BRICS equity markets emanating from the Eurozone, the current study uses two sub-periods: they are (i) the 'crisis' (Panel C) sub-period which spans from $12^{\text {th }}$ August 2009 (following the Greek government defaulting on its debt) to $31^{\text {th }}$ December 2012, and (ii) the 'post-crisis' (Panel D) sub-period that starts on $1^{\text {st }}$ January 2013 and ends on $28^{\text {th }}$ February 2017 in the aftermath of the Eurozone sovereign debt crisis. The present study uses the German DAX composite index as the proxy of the Eurozone (continental Europe) stock market. In other words, the DAX index is used as the "ground zero" host market, and volatility from the DAX index is construed as an exogenous shock to volatility in BRICS markets.

The summary statistics for index returns used to examine cross volatility spillover among BRICS in the stock market, in the aftermath of the Eurozone sovereign debt crisis are presented in Table 2. The Table 2 results seem to be different from the ones obtained during the sub-prime crisis in the US, although individual equity markets recorded lower return in the 'crisis' period compared to the 'pre-crisis' period. In some countries, such as South Africa and Russia, the average market returns in the 'crisis' period seems to be higher compared to the 'post-crisis'. The lowest market returns are recorded in the 'crisis 'period, with the lowest recorded in China $(-0.055)$ and the highest found in South Africa(0.063). The standard deviation as a measure of volatility seems to be relatively high in the 'crisis' period. The highest volatility is recorded in the Russian equity market (1.943) during the 'post-crisis' period. The results in Table 2 seem to indicate that the BRICS stock markets were not affected by volatility spillover from Eurozone countries following the Eurozone sovereign debt crisis.

Table 2. Summary Statistics on Market Returns During the Eurozone Financial Sovereign Debt Crisis

\begin{tabular}{lllllll}
\hline & DAX & BOVESPA & FTSE/JSE & RTS & SENSEX & SSE \\
\cline { 2 - 7 } & \multicolumn{1}{l}{ Panel C: Crisis (turmoil) period: 12 July 2009 to 31 December 2012 } & \\
\hline Mean & 0.044468 & -0.002750 & 0.062721 & 0.046224 & 0.023748 & -0.054964 \\
\hline Median & 0.086221 & 0.041047 & 0.107650 & 0.139754 & 0.045007 & 0.007514 \\
\hline Maximum & 5.491476 & 5.746151 & 3.698099 & 7.23877 & 4.188628 & 4.678913 \\
\hline Minimum & -5.994658 & -8.430565 & -3.693919 & -9.005220 & -6.027934 & -6.982861 \\
& & & & & & \\
\hline Std. Dev. & 1.442582 & 1.454346 & 1.021702 & 1.841829 & 1.155453 & 1.374026 \\
\hline Skewness & -0.142047 & -0.316009 & -0.147496 & -0.356262 & -0.143395 & -0.4671189 \\
\hline Kurtosis & 4.916528 & 5.149921 & 4.015299 & 5.034243 & 4.439856 & 5.27817 \\
\hline
\end{tabular}




\begin{tabular}{lllllll}
\hline Jarque-Bera & $\mathbf{1 2 8 . 5 6 7 3}$ & $\mathbf{1 6 0 . 4 8 2 2}$ & $\mathbf{3 6 . 6 5 6 2 4}$ & $\mathbf{1 6 3 . 3 7 8 6}$ & $\mathbf{6 8 . 5 2 4 8 2}$ & $\mathbf{1 9 6 . 2 9 4 9}$ \\
\hline p-value & 0.0000 & 0.0000 & 0.0000 & 0.0000 & 0.0000 & 0.0000 \\
\hline ARCH(3) & $\mathbf{5 . 2 2 1 4 9 7}$ & $\mathbf{3 . 2 1 2 4 3 0}$ & $\mathbf{4 . 0 1 2 3 2 6}$ & $\mathbf{2 . 7 0 4 5 0 9}$ & $\mathbf{2 . 7 2 8 9 2 6}$ & $\mathbf{5 . 3 3 2 6 2 7}$ \\
\hline p-value & 0.000 & 0.0014 & 0.0001 & 0.0070 & 0.0065 & 0.000 \\
\hline Q(24) & $\mathbf{4 1 . 3 9 6}$ & 25.714 & $\mathbf{3 4 . 2 7 5}$ & 26.168 & 29.728 & 26.088 \\
\hline p-value & 0.015 & 0.368 & 0.080 & 0.345 & 0.194 & 0.349 \\
\hline Qs(24) & $\mathbf{5 3 4 . 7 3}$ & $\mathbf{1 1 0 . 2 8}$ & $\mathbf{2 2 1 . 8 8}$ & $\mathbf{1 3 1 . 4 5}$ & $\mathbf{4 3 . 0 1 5}$ & $\mathbf{1 3 4 . 8 8}$ \\
\hline p-value & 0.0000 & 0.0000 & 0.0000 & 0.0000 & 0.010 & 0.0000 \\
\hline & DAX & BOVESPA & FTSE/JSE & RTS & SENSEX & SSE \\
\cline { 2 - 7 } & Panel D: Post Crisis (stable) period: 1 January & 2013 to 28 February 2017 & \\
\hline Mean & 0.038720 & 0.003587 & 0.012503 & -0.031554 & 0.032846 & 0.033344 \\
\hline Median & 0.109823 & 0.00487 & 0.048937 & -0.088446 & 0.044765 & 0.093064 \\
\hline Maximum & 4.852051 & 6.387348 & -3.944842 & 13.24619 & 5.260866 & 6.02245 \\
\hline Minimum & -7.067271 & -5.108744 & 0.983533 & -13.25455 & -6.11712 & -10.83238 \\
\hline Std. Dev. & 1.224634 & 1.511756 & 0.983533 & 1.943683 & 0.967398 & 1.666913 \\
\hline Skewness & -0.462112 & 0.028707 & -0.329059 & -0.105178 & -0.262231 & -1.256825 \\
\hline Kurtosis & 5.111047 & 3.749273 & 4.31097 & 10.20044 & 6.042261 & 10.26192 \\
\hline & & & & & & \\
\hline Jarque-Bera & $\mathbf{2 2 3 . 0 4 9 8}$ & $\mathbf{2 2 . 6 1 1 8 1}$ & $\mathbf{8 7 . 2 7 5 4 2}$ & $\mathbf{2 2 5 0 . 7 5 4}$ & $\mathbf{3 7 0 . 4 9 4 8}$ & $\mathbf{2 3 4 4 . 9 3 0}$ \\
\hline p-value & 0.0000 & 0.0000 & 0.0000 & 0.0000 & 0.0000 & 0.0000 \\
\hline ARCH(2) & $\mathbf{2 . 7 5 1 9 3 1}$ & $\mathbf{5 . 2 0 6 3 5 0}$ & $\mathbf{6 . 1 3 0 1 1 6}$ & 1.497399 & 1.581475 & $\mathbf{5 . 4 2 4 1 1}$ \\
\hline p-value & 0.0060 & 0.000 & 0.000 & 0.1346 & 0.1142 & 0.000 \\
\hline Q(24) & $\mathbf{5 1 . 4 3 4}$ & 24.318 & 25.239 & 30.309 & 23.564 & $\mathbf{5 8 . 7 9 8}$ \\
\hline p-value & 0.000 & 0.444 & 0.358 & 0.175 & 0.487 & 0.000 \\
\hline Qs(24) & $\mathbf{2 0 6 . 2 3}$ & $\mathbf{2 0 2 . 5 6}$ & $\mathbf{1 9 6 . 1 3}$ & $\mathbf{3 8 9 . 4 5}$ & $\mathbf{3 5 . 9 9 4}$ & $\mathbf{4 1 4 . 7 6}$ \\
\hline & 0.0000 & 0.0000 & 0.0000 & 0.0000 & 0.055 & 0.0000 \\
\hline Source: Est & & & & & & \\
\hline & & & & & \\
\hline
\end{tabular}

Source: Estimation.

Exploratory analysis revealed that the data are not normally distributed as the JB test statistic (with the p-value reported) is significant at all levels, hence the rejection of the null hypothesis of normal distribution. I can also be seen in Table 2 that the data displays serial correlation and hence confirming the existence of autoregressive conditional heteroskedasticity (ARCH) in all the market return and squared return series.

\subsubsection{Unit Root Test}

Table 3 shows the results from the Augmented Dickey-Fuller (ADF), Phillips-Perron (PP) and Kwiatkowski-Phillips-Schmidt-Shin (KPSS) unit root tests. In performing the Augmented Dickey-Fuller (ADF) test, the number of lags of each variable was determined through considering the minimum values of Schwarz-Bayesian Information Criterion (SBIC) statistics (the lags are provided in brackets). The SBIC was chosen because it penalises strongly any term added to the regressors (Brooks, 2014: 427). The results indicate that all variables are stationary. The null hypothesis of unit root is rejected at the $1 \%$ level of significance for ADF and PP test. The stationarity of the $\log$ return series is confirmed with the KPSS, this test operates with the null hypothesis that the series is stationary (i.e. there is no presence of unit root). It can be seen in Table 3 that the KPSS test does not reject the null hypothesis of stationarity. 
Table 3. Unit Root Test on Market Return Indices

\begin{tabular}{|c|c|c|c|c|c|c|}
\hline \multirow[b]{2}{*}{ Variable } & \multicolumn{2}{|c|}{$\mathrm{ADF}$} & \multicolumn{2}{|c|}{ PP } & \multicolumn{2}{|c|}{ KPSS } \\
\hline & $\mathrm{Z}(\mathrm{t})$ & $5 \%$ crit. Value & $\bar{Z}(\mathrm{t})$ & $5 \%$ crit. Value & $\mathrm{Z}(\mathrm{t})$ & $5 \%$ crit. Value \\
\hline S\&P500 & $-7.301686^{* * *[16]}$ & -2.863672 & $-59.13932 * * *$ & -2.862405 & 0.121491 & 0.463000 \\
\hline$\Delta$ S\&P500 & $-9.510465^{* * *}[26]$ & -2.866195 & $-374.8628 * * * *$ & -2.862445 & 0.020117 & 0.463000 \\
\hline DAX & $-11.87209 * * *[17]$ & -2.862552 & $-54.44152 * * *$ & -2.862339 & 0.063877 & 0.463000 \\
\hline$\triangle \mathrm{DAX}$ & $-16.03637 * * *[26]$ & -2.862725 & $-527.6982 * *$ & -2.862350 & 0.112488 & 0.463000 \\
\hline BOVESPA & $-4.341675 * * *[25]$ & -2.866091 & $-52.31418 * * *$ & -2.862435 & 0.147160 & 0.463000 \\
\hline$\triangle$ BOVESPA & $-8.012553 * * *[26]$ & -2.866805 & $-253.7464 * *$ & -2.862485 & 0.072026 & 0.463000 \\
\hline FTSE/JSE & $-16.19319 * * *[8]$ & -2.862700 & $-51.25948 * * *$ & -2.862399 & 0.223617 & 0.463000 \\
\hline$\Delta$ FTSE/JSE & $-11.48140 * * *[25]$ & -2.863972 & $-244.8472 * * *$ & -2.862434 & 0.037069 & 0.463000 \\
\hline RTS & $\left.-7.810455^{* * *} * 28\right]$ & -2.862309 & $-49.51719 * * *$ & -2.862301 & 0.223071 & 0.463000 \\
\hline$\Delta \mathrm{RTS}$ & $-19.89440 * * *[1]$ & -2.862309 & $-645.8037 * * *$ & -2.862301 & 0.025802 & 0.463000 \\
\hline SENSEX & $-7.647694 * * *[21]$ & -2.864364 & $-50.17779 * * *$ & -2.862459 & 0.168615 & 0.463000 \\
\hline$\triangle$ SENSEX & $-9.061033 * * *[26]$ & -2.865093 & $-404.9063 * * *$ & -2.862517 & 0.055367 & 0.463000 \\
\hline SSE & $-14.21251 * * *[9]$ & -2.862640 & $-51.48340 * * *$ & -2.862403 & 0.152435 & 0.463000 \\
\hline$\Delta \mathrm{SSE}$ & $-13.99533^{* * *}[23]$ & -2.863246 & $-278.5603 * *$ & -2.862426 & 0.554594 & 0.463000 \\
\hline
\end{tabular}

Source: Estimation

Experiments with more lags in the augmented regression yielded the same conclusion. It should also be drawn to the reader's attention that when the variables are differenced the results become more significant, hence confirming the stationarity of the series.

\subsubsection{Unconditional Correlation}

As a preliminary analysis, the unconditional correlation among variables is examined. Table 4 shows the correlation coefficient between the composite return indices used in the present study. The highest correlation is found between the U.S. and the Brazilian stock markets (0.664002), followed by the correlation between South Africa and Russia (0.641089), whereas the lowest correlation coefficient is observed between the U.S. and Chinese markets (0.064352).

From the point of view of the U.S. stock market as a source market for the transmission of shocks, it can be seen in Table 4 that the U.S. stock market is highly correlated with the Brazilian stock market. The high correlation can be a sign of a significant regional transmission due to geographic proximity between the two countries and high interdependence between the two markets. As from the point of view the Eurozone as the source market, Table 4 shows that the FTSE/JSE (South Africa) has the highest correlation with the DAX, while SSE (China) has the lowest correlation.

It is worth noting that, in general, the Chinese stock market has the lowest correlation with any stock market under consideration. This can be explained by the fact that the Chinese equity market is still primarily driven by local retail investors, who hold close to $50 \%$ of the market's total free-float market capitalisation and account for $80 \%$ of total trading volume $(\mathrm{Lu}, 2019)$. This is also because, for an extended period, Chinese authorities barred foreigners from investing in A-shares. Chinese A-shares are RMB-denominated equity shares of China-based companies and trade on either the Shanghai Stock Exchange (SSE) or Shenzhen Stock Exchange (SZSE). 
Table 4. Unconditional Correlation Matrix of Market Returns

\begin{tabular}{lrlrlrrr}
\hline & BOVESPA & \multicolumn{1}{l}{ DAX } & JSE & RTS & \multicolumn{1}{l}{ S\&P500 } & SENSEX & \multicolumn{1}{l}{ SSE } \\
\hline BOVESPA & 1 & 0.512471 & 0.463959 & 0.469762 & 0.664002 & 0.290545 & 0.146914 \\
DAX & 0.512471 & 1 & 0.625136 & 0.563563 & 0.644323 & 0.408316 & 0.109419 \\
JSE & 0.463959 & 0.625136 & 1 & 0.641089 & 0.411096 & 0.443092 & 0.164732 \\
RTS & 0.469762 & 0.563563 & 0.641089 & 1 & 0.388643 & 0.432924 & 0.192757 \\
S\&P500 & 0.664002 & 0.644323 & 0.411096 & 0.388643 & 1 & 0.254042 & 0.064352 \\
SENSEX & 0.290545 & 0.408316 & 0.443092 & 0.432924 & 0.254042 & 1 & 0.222381 \\
SSE & 0.146914 & 0.109419 & 0.164732 & 0.192757 & 0.064352 & 0.222381 & 1 \\
\hline
\end{tabular}

Source: Estimation

\subsection{Methodology}

This section discusses Diagonal VECH version of the multivariate generalized autoregressive conditional heteroskedasticity (MGARCH) model that will be used to examine volatility spillover in BRICS stock markets following the financial crises that took place in the U.S. and Eurozone countries. In order to gain more insights on how the Diagonal VECH GARCH model is derived the Full -VECH Model is discussed first.

\subsubsection{Multivariate Garch Models}

Following pioneering work by Engle (1982) and Bollerslev (1986), comprehensive literature on conditional volatility modelling was developed. The initial models were quickly extended into multivariate versions. Multivariate GARCH models are normally used to examine how equity markets are inter-related, as volatilities of financial series are known to move synchronously across different markets or be slightly delayed. Multivariate GARCH models are in essence very similar to their univariate counterparts, except that they also specify equations for how the covariances move over time. Several different multivariate GARCH formulations have been proposed in the literature, this article focuses uses the Diagonal VECH (Note 2) model and it is discussed below.

\subsubsection{The Full-VECH Model}

A common specification VECH model proposed initially by Bollerslev, Engle and Wooldridge (1988) is as follows:

$$
\operatorname{VECH}\left(H_{t}\right)=C+A \operatorname{VECH}\left(u_{t} u_{t-1}^{\prime}\right)+B \operatorname{VECH}\left(H_{t-1}\right)
$$

With

$$
u_{t} \mid \psi_{t-1} \sim N\left(O, H_{t}\right)
$$

where $H_{t}$ is a $2 \times 2$ conditional variance-covariance matrix, $\boldsymbol{u}_{t}$ is a $2 \times 1$ disturbance vector, $\psi_{t-1}$ represents the information set at time $t-1, \mathrm{C}$ is a $3 \times 1$ parameter vector, $\mathrm{A}$ and $\mathrm{B}$ are $3 \times 3$ parameter matrices, and $\mathrm{VECH}($.) denotes the column-stacking operator applied to the upper portion of the symmetric matrix. The model requires the estimation of 21 parameters. The elements of the VECH are as follows:

$$
\begin{gathered}
H_{t}=\left[\begin{array}{ll}
h_{11 t} & h_{12 t} \\
h_{21 t} & h_{22 t}
\end{array}\right], u_{t}=\left[\begin{array}{l}
u_{1 t} \\
u_{2 t}
\end{array}\right], C=\left[\begin{array}{l}
c_{11} \\
c_{21} \\
c_{31}
\end{array}\right] \\
A=\left[\begin{array}{lll}
a_{11} & a_{12} & a_{13} \\
a_{21} & a_{22} & a_{23} \\
a_{31} & a_{32} & a_{33}
\end{array}\right], B=\left[\begin{array}{lll}
b_{11} & b_{12} & b_{13} \\
b_{21} & b_{22} & b_{23} \\
b_{31} & b_{32} & b_{33}
\end{array}\right]
\end{gathered}
$$

The VECH operator takes the 'upper triangular' portion of a matrix and stacks each element into a vector with a single column. For example, in the case of $V E C H(H t)$, this becomes 


$$
\operatorname{VECH}\left(H_{t}\right)=\left[\begin{array}{l}
h_{11 t} \\
h_{22 t} \\
h_{12 t}
\end{array}\right]
$$

with $h_{i i t}$ representing the conditional variances at time $t$ of the two return series $(i=1,2)$ used in the model, and $h_{i j t}(i$ $\neq j$ ) representing the conditional covariances between the asset returns. In the case of $V E C H\left(u_{t} u_{t}^{\prime}\right)$ this can be expressed as:

$$
\begin{aligned}
\operatorname{VECH}\left(u_{t} u_{t}^{\prime}\right) & =\operatorname{VECH}\left(\left[\begin{array}{l}
u_{1 t} \\
u_{2 t}
\end{array}\right]\left[\begin{array}{ll}
u_{1 t} & u_{2 t}
\end{array}\right]\right) \\
& =\operatorname{VECH}\left(\begin{array}{cc}
u_{1 t}^{2} & u_{1 t} u_{2 t} \\
u_{1 t} u_{2 t} & u_{2 t}^{2}
\end{array}\right) \\
& =\left[\begin{array}{c}
u_{1 t}^{2} \\
u_{2 t}^{2} \\
u_{1 t} u_{t}
\end{array}\right]
\end{aligned}
$$

The VECH model in full is given by:

$$
\begin{aligned}
& h_{11 t}=c_{11}+a_{11} u_{2 t-1}^{2}+a_{12} u_{2 t-1}^{2}+a_{13} u_{2 t-1}+b_{11} h_{11 t-1}+b_{12} h_{22 t-1}+b_{13} h_{12 t-1} \\
& h_{22 t}=c_{21}+a_{21} u_{2 t-1}^{2}+a_{22} u_{2 t-1}^{2}+a_{23} u_{2 t-1}+b_{21} h_{11 t-1}+b_{22} h_{22 t-1}+b_{23} h_{12 t-1} \\
& h_{12 t}=c_{31}+a_{31} u_{1 t-1}^{2}+a_{32} u_{2 t-1}^{2}+a_{33} u_{2 t-1}+b_{31} h_{11 t-1}+b_{32} h_{22 t-1}+b_{33} h_{12 t-1}
\end{aligned}
$$

In this way, it is evident that the conditional variances and conditional covariances depend on the lagged values of all of the conditional variances of, and conditional covariances between, all of the asset returns in the series, as well as the lagged squared errors and the error cross-products.

\subsubsection{The Diagonal VECH Model}

As discussed in Section 2.2.1.1 above, the simple two series, the conditional variance, and covariance equations for the unrestricted $V E C H$ model contain 21 parameters. As the number of series used in the model increases, the estimation of the VECH model can quickly become cumbersome and even infeasible. Hence the VECH model's conditional variance-covariance matrix has been restricted to the form developed by Bollerslev, Engle, and Wooldridge (1988), in which $A$ and $B$ in Equation 1 are assumed to be diagonal. This reduces the number of parameters to be estimated to 9 , with $A$ and $B$ each having 3 elements. The model, known as a diagonal $V E C H$, is now characterised by:

$$
h_{i j, t}=c_{i j}+\alpha_{i j} u_{i, t-1} u_{j, t-1}+\beta_{i j} h_{i j, t-1}
$$

for $i, j=1,2$,

where $c_{i j}, \alpha_{i j}$ and $\beta_{i j}$ are parameters. The diagonal VECH multivariate GARCH model could also be expressed as a geometrically declining average of past cross products of unexpected returns, with recent observations carrying higher weights.

The diagonal VECH multivariate GARCH $(1,1)$ in full is thus given by:

$$
\begin{gathered}
h_{11 t}=c_{1}+\alpha_{11} u_{1, t-1}^{2}+\beta_{11} h_{11, t-1} \\
h_{22 t}=c_{2}+\alpha_{22} u_{2, t-1}^{2}+\beta_{22} h_{22, t-1} \\
h_{12 t}=c_{3}+\alpha_{33} u_{1, t-1} u_{2, t-1}+\beta_{33} h_{12, t-1}
\end{gathered}
$$

The diagonal VECH multivariate GARCH estimation uses maximum likelihood to jointly estimate the parameters of the mean and the variance equations. Assuming multivariate normality, the log-likelihood contributions for GARCH models are given by:

and

$$
l_{t}=-\frac{1}{2} \operatorname{mlog}(2 \pi)-\frac{1}{2} \log \left|H_{t}\right|-\frac{1}{2} \varepsilon_{t}^{\prime} H_{t}^{-1} \varepsilon_{t}
$$

where $\mathrm{m}$ is the number of mean equation residual. For student's $\mathrm{t}$-distribution, the contributions are in the form: 


$$
l_{t}=\log \left\{\frac{\Gamma\left(\frac{v+m}{2}\right) v^{\frac{m}{2}}}{(v \pi)^{\frac{m}{2}} \Gamma\left(\frac{v}{2}\right)(v-2)^{\frac{m}{2}}}\right\}-\frac{1}{2} \log \left(\left|H_{t}\right|\right)-\frac{1}{2}(v+m) \log \left[1+\frac{\varepsilon_{t}^{\prime} H_{t}^{-1} \varepsilon_{t}}{v-2}\right]
$$

where $\mathrm{v}$ is the estimated degree of freedom.

\section{Results of Empirical Models and Discussion}

As shown in Table 1, the returns series distribution are not normal; hence the present study uses the student's $\mathrm{t}$-distribution. The results for VECH models following the sub-prime crisis and the Eurozone sovereign debt crises are discussed below.

\subsection{VECH GARCH Estimations for Financial Contagion in BRICS Countries Following the Sub-prime Crisis}

In order to analyse volatility spillover from the U.S. to individual BRICS equity markets in the wake of the sub-prime financial crisis the current study divide the data into two sub-periods namely the (i) 'pre-crisis'(stable) sub-period that ranges between $11^{\text {th }}$ February 2005 and $1^{\text {st }}$ February 2007 and (ii) the 'crisis' sub-period that extends from $2^{\text {nd }}$ February 2007, the explosion of the real estate bubble in the U.S., to $10^{\text {th }}$ July 2009. The main thrust is to examine the change in correlation between the two sub-periods.

Tables 5 and 6 present estimated coefficients for mean equation $\left(\mu_{1}\right.$ and $\left.\mu_{2}\right)$ and the diagonal (bivariate) VECH GARCH model $\left(c_{11}, c_{22}, c_{12}, \alpha_{11}, \alpha_{22}, \alpha_{12}, \beta_{11}, \beta_{22}, \beta_{12}\right)$ for pairwise correlations between individual BRICS equity markets vis-à-vis the U.S. market.

Table 5. Parameter Estimation for Bivariate Diagonal VECH $(1,1)$ Equation for Conditional Correlation with Pairs of the U.S. (as the source) and Individual BRCS Market (as target markets) in Pre-Crisis Period

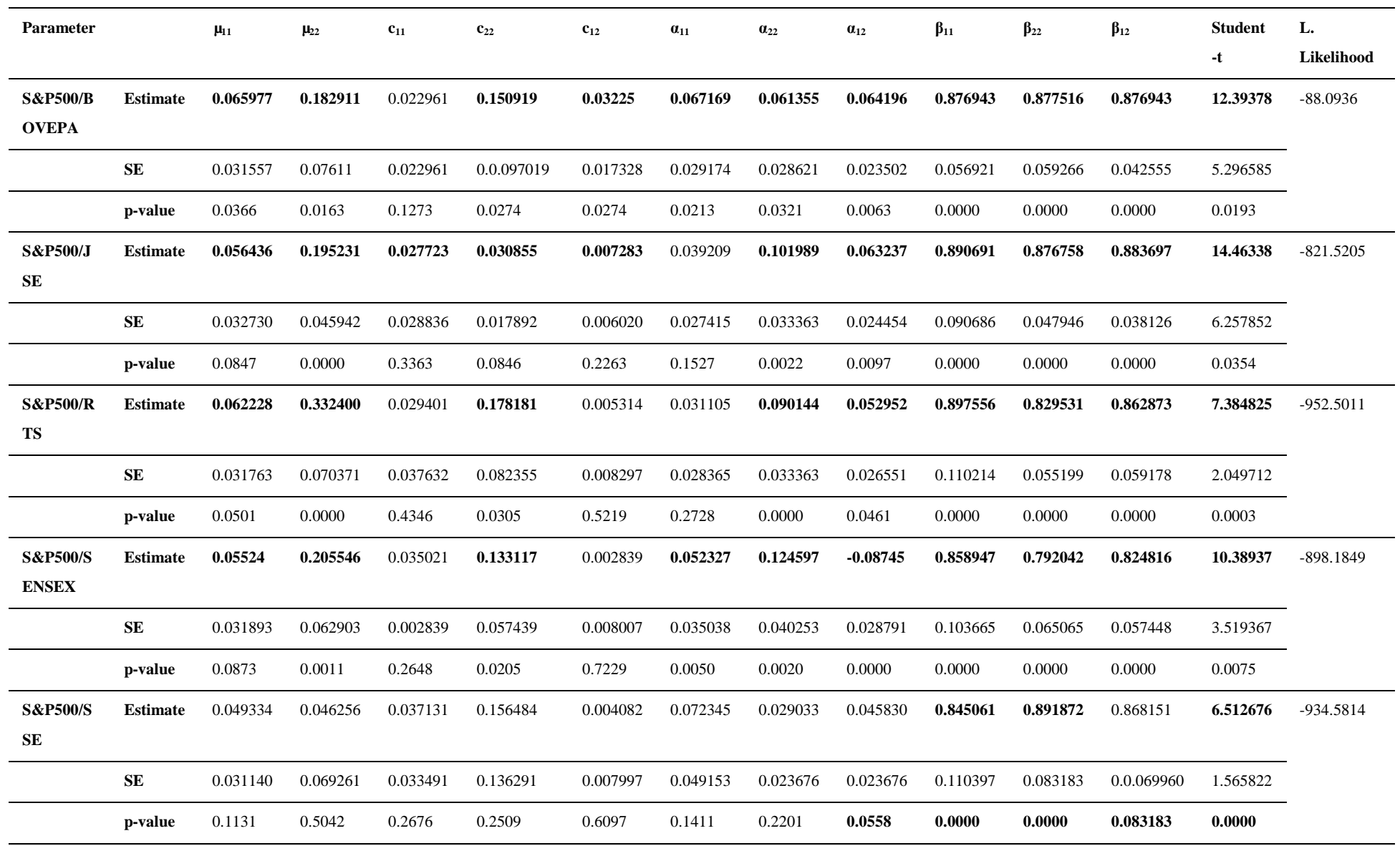

Subscript $\mathrm{i}=\mathrm{j}=1$ indicates parameter estimate for the U.S. stock markets, whereas $\mathrm{i}=\mathrm{j}=2$ indicates estimates for individual BRICS stock markets.

Source: Estimation. 
Table 6. Parameter Estimation for Bivariate Diagonal VECH $(1,1)$ Equation for Conditional Correlation with the U.S. in Crisis Period'

\begin{tabular}{|c|c|c|c|c|c|c|c|c|c|c|c|c|c|c|}
\hline Parameter & & $\mu_{11}$ & $\mu_{22}$ & $\mathrm{c}_{11}$ & $\mathbf{c}_{22}$ & $c_{12}$ & $\alpha_{11}$ & $\alpha_{22}$ & $\alpha_{12}$ & $\beta_{11}$ & $\beta_{22}$ & $\beta_{12}$ & $\begin{array}{l}\text { Student } \\
-t\end{array}$ & $\begin{array}{l}\text { L. } \\
\text { Likelihood }\end{array}$ \\
\hline S\&P500/BOVE & Estimate & 0.057029 & 0.221806 & 0.033439 & 0.130154 & 0.057950 & 0.087774 & 0.092022 & 0.090223 & 0.915337 & 0.902884 & 0.909089 & 4.801781 & -1478.155 \\
\hline \multirow[t]{3}{*}{ PA } & & & & & & & & 3 & & & & & & \\
\hline & SE & 0.055964 & 0.090318 & 0.013775 & 0.067152 & 0.026408 & 0.021543 & 0.026762 & 0.022738 & 0.015750 & 0.02608 & 0.018160 & 0.976208 & \\
\hline & p-value & 0.3082 & 0.0141 & 0.0152 & 0.0526 & 0.0282 & 0.0282 & 0.0005 & 0.0001 & 0.0000 & 0.0000 & 0.0000 & 0.0000 & \\
\hline \multirow[t]{3}{*}{ S\&P500/JSE } & Estimate & 0.028255 & 0.079651 & 0.040825 & 0.086742 & 0.022177 & 0.081182 & 0.094857 & 0.086742 & 0.910400 & 0.887640 & 0.898948 & 8.653345 & -1545.178 \\
\hline & SE & 0.063976 & 0.071340 & 0.016402 & 0.050130 & 0.014187 & 0.022332 & 0.032943 & 0.020785 & 0.016402 & 0.034921 & 0.021719 & 2.603757 & \\
\hline & p-value & 0.6587 & 0.2642 & 0.0128 & 0.0836 & 0.1180 & 0.0003 & 0.0040 & 0.0000 & 0.0000 & 0.0000 & 0.000 & 0.0009 & \\
\hline \multirow[t]{3}{*}{ S\&P500/RTS } & Estimate & 0.044705 & 0.145865 & 0.038036 & 0.075881 & 0.014577 & 0.088144 & 0.079179 & 0.083542 & 0.909614 & 0.917062 & 0.913331 & 6.532378 & -1685.720 \\
\hline & SE & 0.063238 & 0.086891 & 0.016748 & 0.039633 & 0.013244 & 0.024404 & 0.021307 & 0.017849 & 0.020703 & 0.020730 & 0.020730 & 1.532409 & \\
\hline & p-value & 0.4796 & 0.0932 & 0.0231 & 0.0555 & 0.2711 & 0.0003 & 0.0002 & 0.0000 & 0.0000 & 0.0000 & 0.0000 & 0.0000 & \\
\hline \multirow{4}{*}{$\begin{array}{l}\text { S\&P500/SENS } \\
\text { EX }\end{array}$} & Estimate & 0.04071 & 0.205004 & 0.040865 & 0.246729 & 0.022921 & 0.084203 & 0.156754 & 0.114887 & 0.913350 & 0.817735 & 0.864221 & 5.974179 & -1660.335 \\
\hline & & & & & & & & & & & & & & \\
\hline & SE & 0.061399 & 0.088194 & 0.017241 & 0.116975 & 0.022763 & 0.024710 & 0.04786 & 0.026668 & 0.021271 & 0.048063 & 0.028340 & 1.143466 & \\
\hline & p-value & 0.5098 & 0.0201 & 0.0178 & 0.0349 & 0.3140 & 0.0007 & 0.0011 & 0.0000 & 0.0000 & 0.0000 & 0.0000 & 0.0000 & \\
\hline \multirow[t]{3}{*}{ S\&P500/SSE } & Estimate & 0.031901 & 0.292355 & 0.032017 & 0.110912 & 0.003083 & 0.085880 & 0.061381 & 0.072604 & 0.915179 & 0.922704 & 0.915179 & 6.060515 & -1711.522 \\
\hline & SE & 0.061046 & 0.101503 & 0.016189 & 0.127293 & 0.015944 & 0.025401 & 0.023592 & 0.018398 & 0.021124 & 0.033477 & 0.020008 & 1.384365 & \\
\hline & p-value & 0.6013 & 0.0040 & 0.0480 & 0.3836 & 0.8467 & 0.0007 & 0.0093 & 0.0001 & 0.0000 & 0.0000 & 0.0000 & 0.0000 & \\
\hline
\end{tabular}

Subscript $\mathrm{i}=\mathrm{j}=1$ indicates parameter estimate for the U.S. stock markets, whereas $\mathrm{i}=\mathrm{j}=2$ indicates estimates for individual BRICS stock markets.

Source: Estimation.

From Table 5 it can be seen that during the 'pre-crisis' period the own-mean spillover coefficients $\left(\mu_{22}\right)$, in BRICS stock markets are significant at the $1 \%$ level except for China. The own-mean spillovers vary between the largest 0.332400 (Russia) and the smallest 0.046256 (China). The cross-mean coefficient estimate $\left(\mu_{11}\right)$, indicating mean spillovers from the U.S. market, vary between the largest 0.06598 (Brazil) and the smallest 0.049334 (China).

Parameter estimates $\alpha_{22}$ indicating own innovation (ARCH effect) spillover in individual BRICS stock markets are significant except for China and fluctuate from 0.124597(India) to 0.029033(China). This points towards the presence of ARCH effects, where the precedent shocks occurring from the one market will have the strongest impact on its future market volatility compared to the shocks stemming from the U.S. market. Parameter estimates $\alpha_{12}$ indicate cross-innovation spillover between the U.S. and individual BRICS stock markets. It can be seen in Table 5 that all cross-innovation spillover coefficients are significant at the 5\% level and their magnitude is lower compared to own innovation spillover coefficients $\alpha_{22}$ (except BOVESPA). The strongest $\alpha_{12}$ coefficient is found in Brazil (0.064196), while the weakest is recorded in India (-0.083010). Based on the magnitudes of the estimated cross-volatility coefficients, innovation in all of the BRICS stock indices is influenced by the instability from the U.S. stock market, but the own-volatility shocks are relatively bigger than the cross-volatility shocks. Put another way, past volatility shocks in individual markets have a larger effect on their own future unpredictability than past volatility shocks occurring from the US. Hence the conclusion that lagged country-specific shocks (ARCH influence) do add to the BRICS stock market volatility of any given country in a recursive way.

During the 'pre-crisis' period, the coefficient for own conditional volatility (GARCH effect) $\left(\beta_{22}\right)$ is significant at all levels. The largest value is 0.891872 (China), while the lowest is 0.792042 (India). This indicates the persistence of volatility in all BRICS stock market returns. Similarly, the cross- conditional volatility coefficients $\left(\beta_{12}\right)$ are significant and are slightly higher in magnitude compared to the $\beta_{22}$ coefficient. The highest $\beta_{12}$ is found in South Africa (0.883697), while the lowest is in India (0.862873). High $\beta_{12}$ estimates compared to $\beta_{22}$ implies that precedent shocks occurring from the U.S. markets have a greater impact on BRICS stock markets than own lagged market volatility. 
In Table 6 results for the 'crisis' period are similar to the ones obtained in the 'pre-crisis' period, for instance, the ARCH effects as expressed by coefficient estimate $\alpha_{22}$ are significant at the $1 \%$ level and seem to be higher in magnitude compared to the cross volatility coefficient $\alpha_{12}$. The highest ARCH effect recorded is 0.156754 (India) and the lowest is 0.061381 (China), whereas the cross-innovation spillover volatility coefficient $\alpha_{12}$ ranges between 0.090223 (Brazil) and 0.072604 (China). Similarly, the GARCH effect as expressed by the $\beta_{22}$ coefficients is lower compared to cross-conditional volatility coefficient $\beta_{12}$, suggesting that precedent shocks occurring from the U.S. markets have a greater impact on BRICS stock markets than own lagged market volatility.

It is also worth noting that its own conditional correlation and cross-correlation (covariance) are significantly stronger during the 'crisis' period compared to the 'pre-crisis' period. Figures 8 to 13 present conditional variance and covariance plots from by diagonal VECH GARCH for both the 'pre-crisis' period and the 'crisis' period. The plots show a significant increase in conditional covariance during the 'crisis' period, with the exception of the Chinese stock market.

It can also be seen in Figures 8 to 12 that for all stock markets, with the exception of the Chinese market, the conditional covariance reached the highest in the $4^{\text {th }}$ quarter of 2008. Similar results are obtained with the conditional correlation plots from Figure 13 to 17 where the conditional correlation in the 'crisis' period is higher in magnitude compared to the 'pre-crisis' period. A higher conditional correlation during the 'crisis' period is indicative of the presence of financial contagion between the US and individual BRICS market (with the exception of Chinese market). These results are in line with Kenourgios and Dimitriou (2015), Mohti, Dionísio, Vieira and Ferreira (2019) and Niyitegeka and Tewari (2021) who found evidence of financial contagion in emerging market during the Subprime crisis.

In Tables 5 and 6 the student's t-distribution and Log-likelihood are also presented. This Student's t-test has a coefficient estimated for the degrees of freedom of the distribution. The coefficients student's t-distribution is statistically significant at $1 \%$ and are between 6 and 14 .

It needs to be noted that, in order to have a defined variance the degrees of freedom have to be greater than 2 , hence the conclusion that with the diagonal VECH model the variance is well defined. Additionally, as we know, the student's t-distribution tends towards the normal distribution when we consider infinite degrees of freedom. Having such small figures (still well defined as mentioned before) leads us to believe, and confirm, that our data follow, most likely, a heavy-tailed distribution.

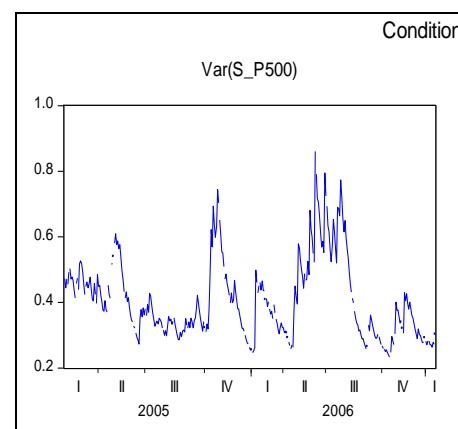

Cov(S_P500,BOVESPA)

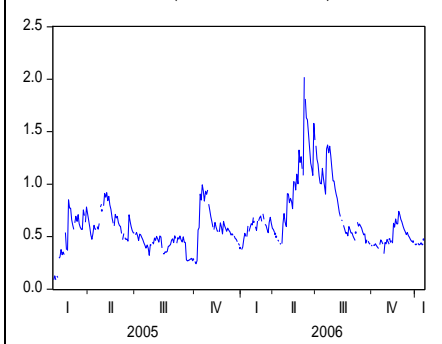

$\operatorname{Var}(B O V E S P A)$

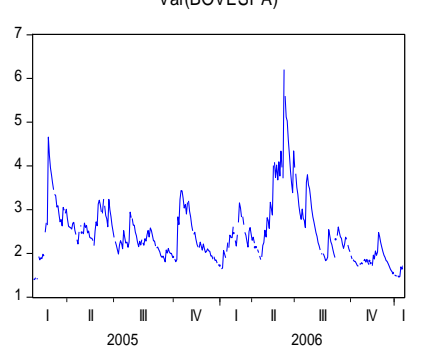

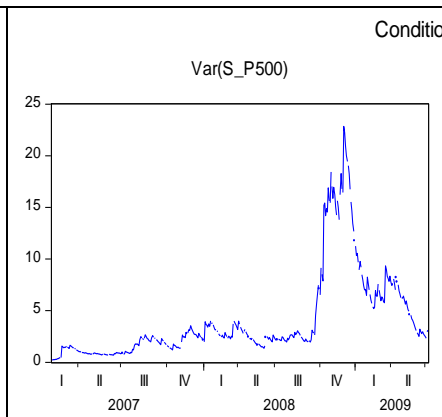

Cov(S_P500,BOVESPA)

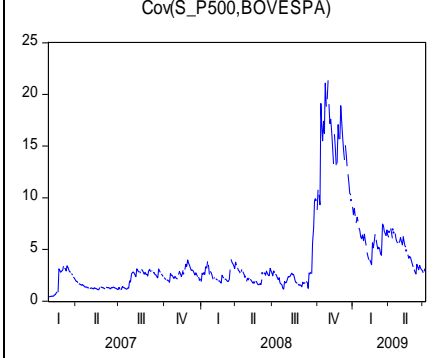

$\operatorname{Var}($ BOVESPA)

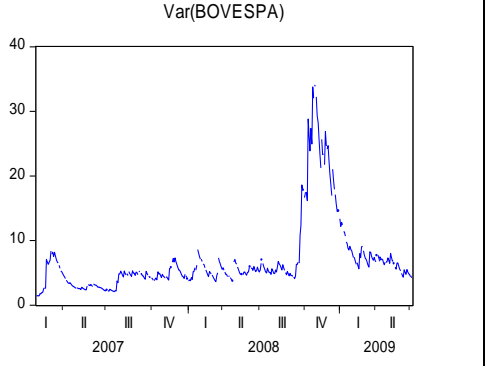

Figure 8. Conditional Variance and Covariance using Diagonal VECH GARCH under Student's t-distribution for 'Pre-crisis' Period (left) and 'Crisis' Period (right) where S\&P500 represents the U.S. Stock Market, and BOVESPA represents the Brazilian Stock Market 


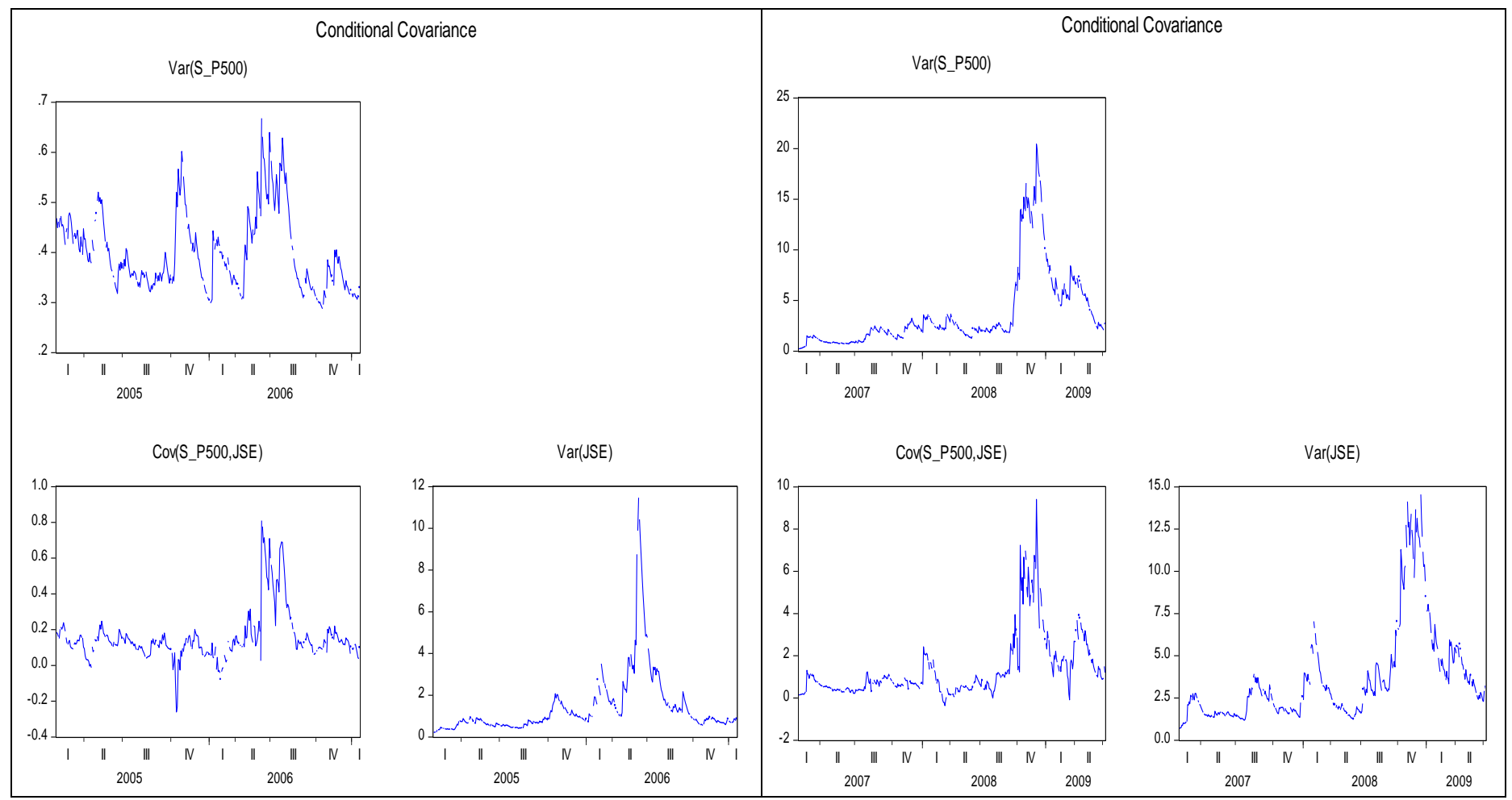

Figure 9. Conditional Variance and Covariance using Diagonal VECH GARCH under Student's t-distribution, for

'Pre-crisis' Period (left) and 'Crisis' Period (right) where S\&P500 represents the U.S. Stock Market, and FTSE/JSE represents the South African Stock Market

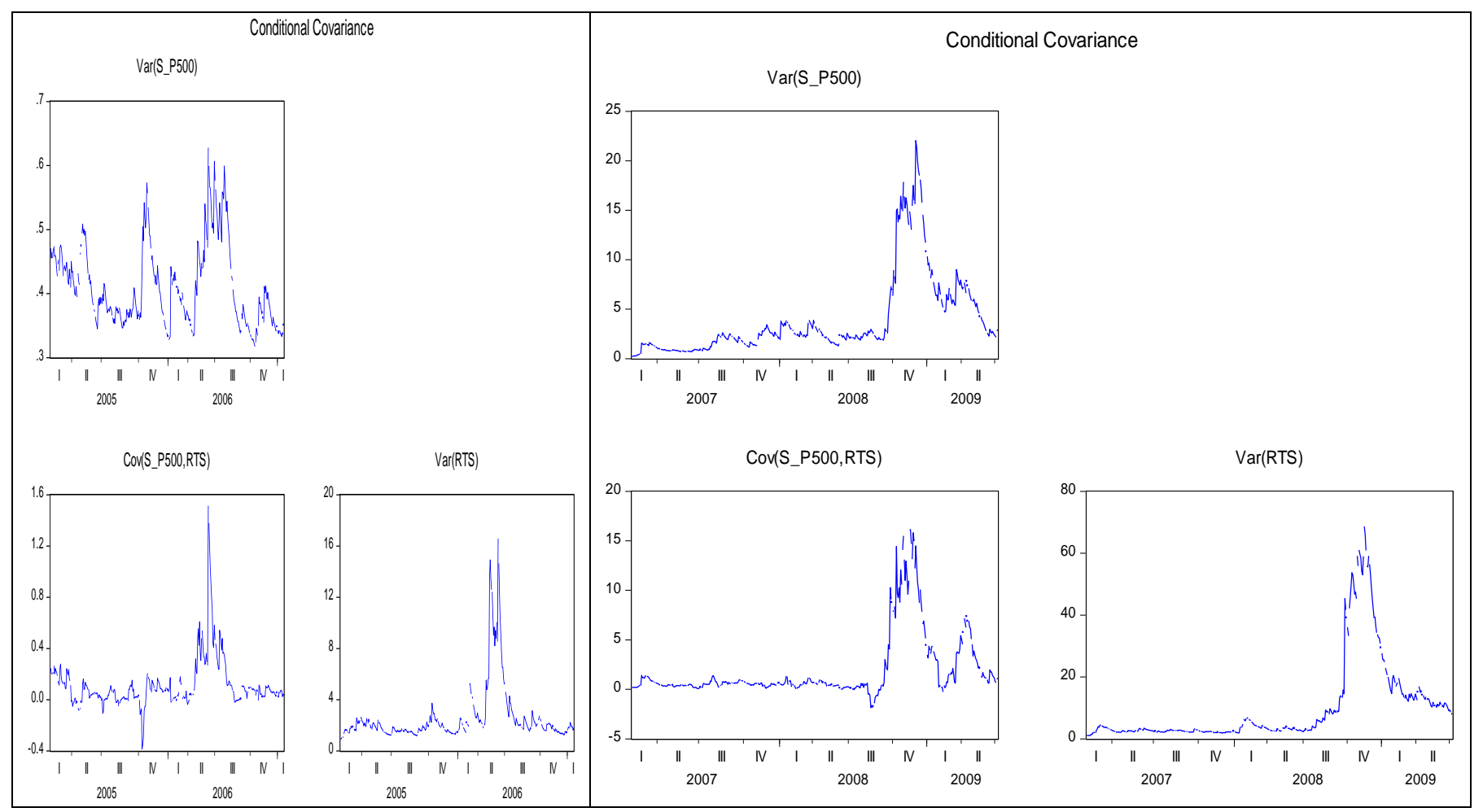

Figure 10. Conditional Variance and Covariance using Diagonal VECH GARCH under Student's t-distribution, for 'Pre-crisis' Period (left) and 'Crisis' Period (right) where S\&P500 represents the U.S. Stock Market, and RTS represents the Russian Stock Market 


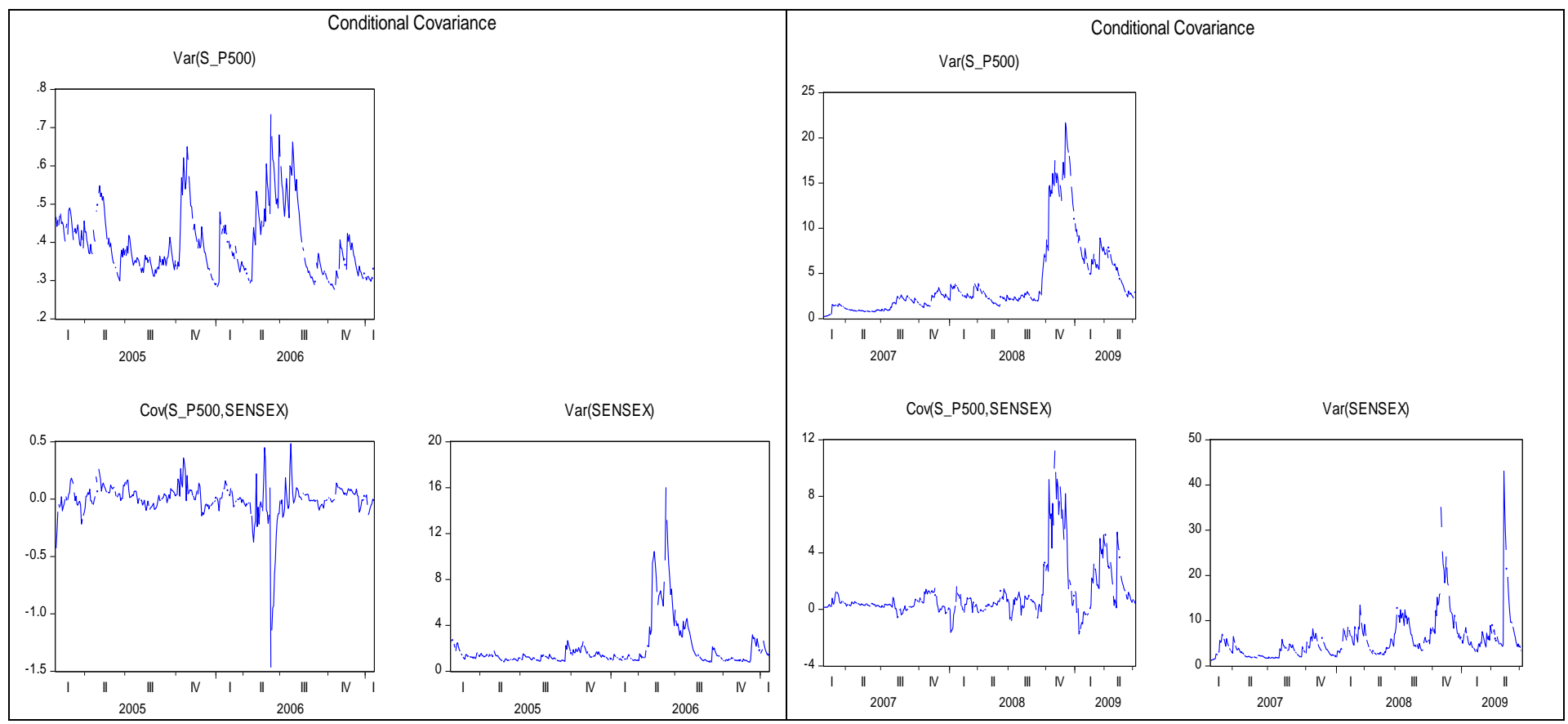

Figure 11. Conditional Variance and Covariance using Diagonal VECH GARCH under Student's t-distribution, for

'Pre-crisis' Period (left) and 'Crisis' Period (right) where S\&P500 represents the U.S. Stock Market, and SENSEX represents the Indian Stock Market

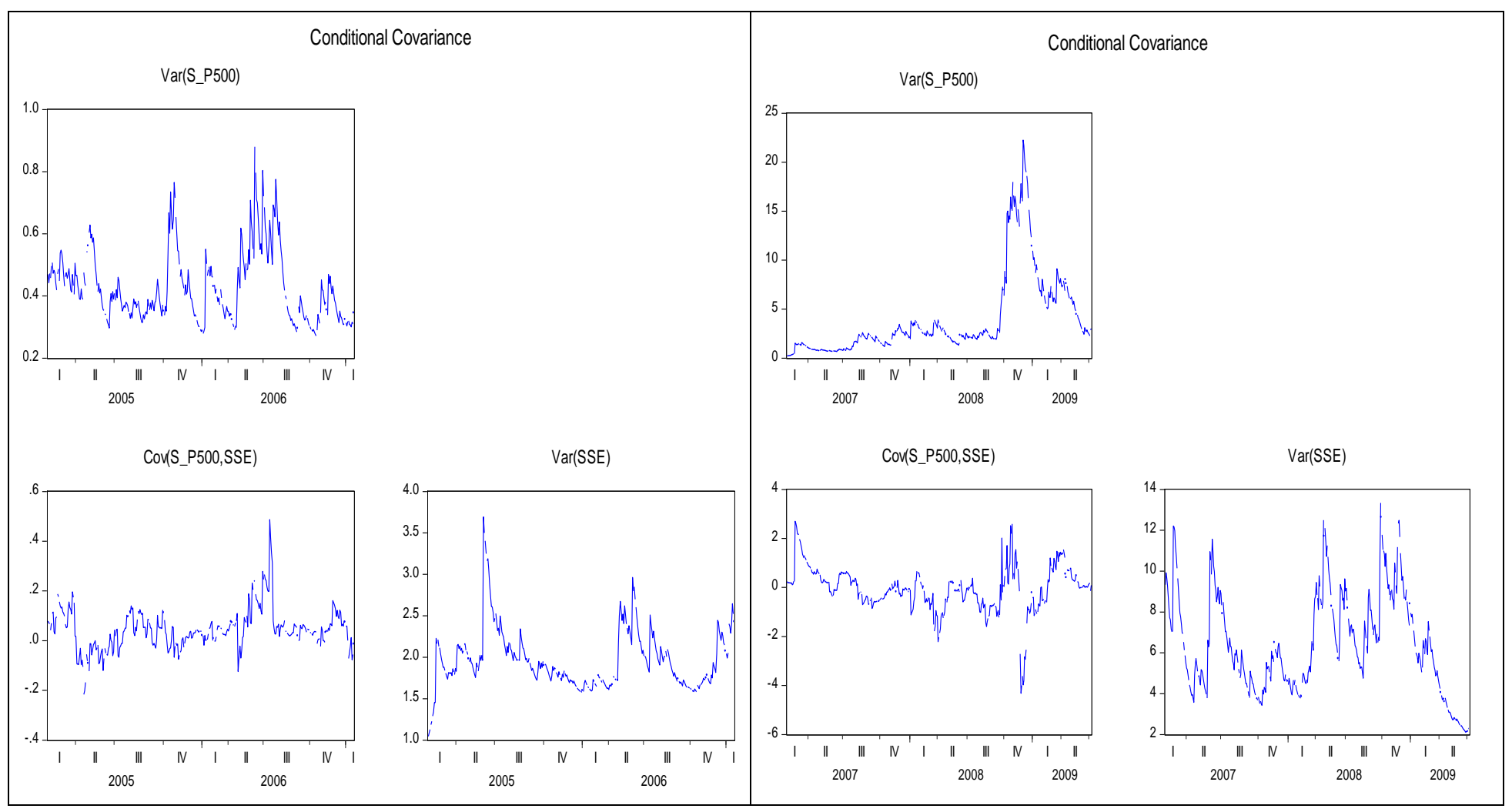

Figure 12. Conditional Variance and Covariance using Diagonal VECH GARCH under Student's t-distribution, for 'Pre-crisis' Period (left) and 'Crisis' Period (right) where S\&P500 represents the U.S. Stock Market, and SSE represents the Chinese Stock Market 


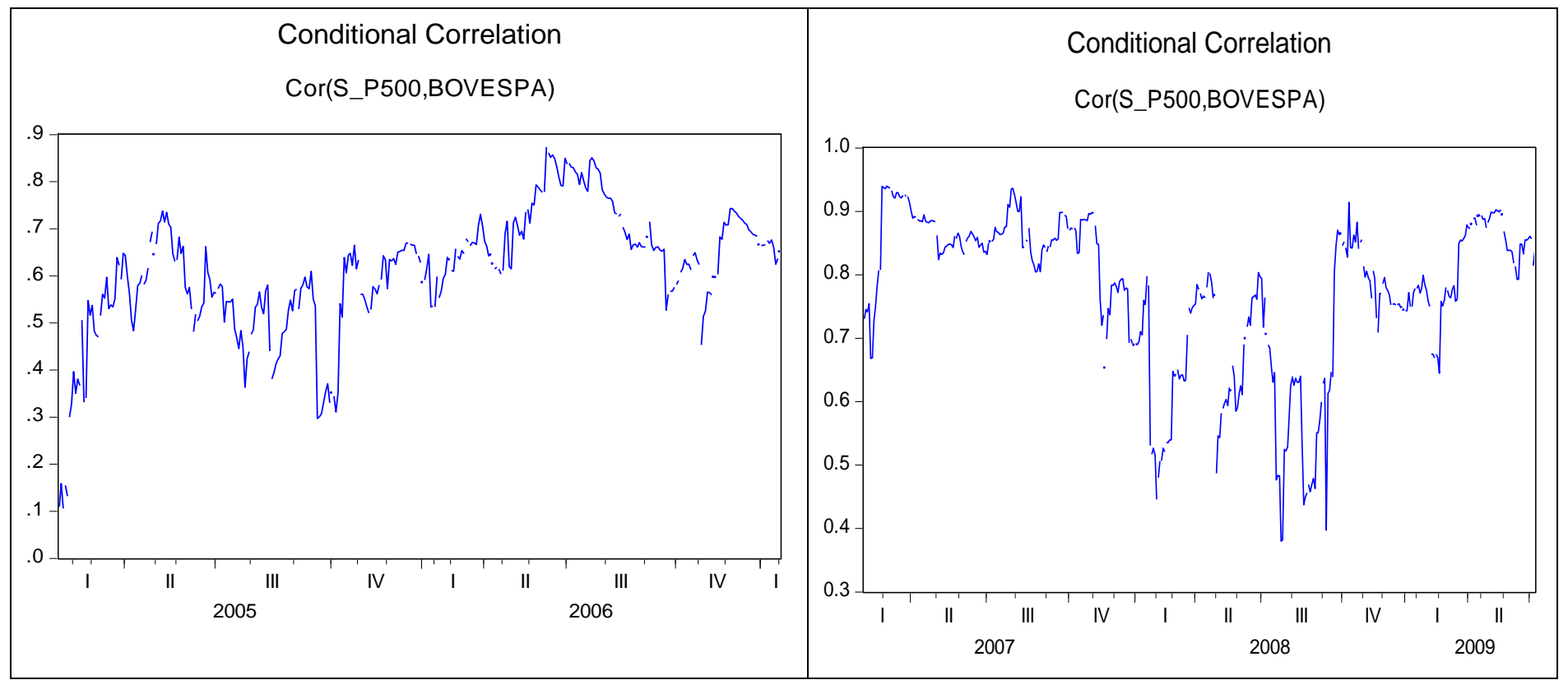

Figure 13. Conditional Correlation using Diagonal VECH GARCH under Student's t-distribution for 'Pre-crisis' Period (left) and 'Crisis' Period (right) where S\&P500 represents the U.S. Stock Market, and BOVESPA represents the Brazilian Stock Market

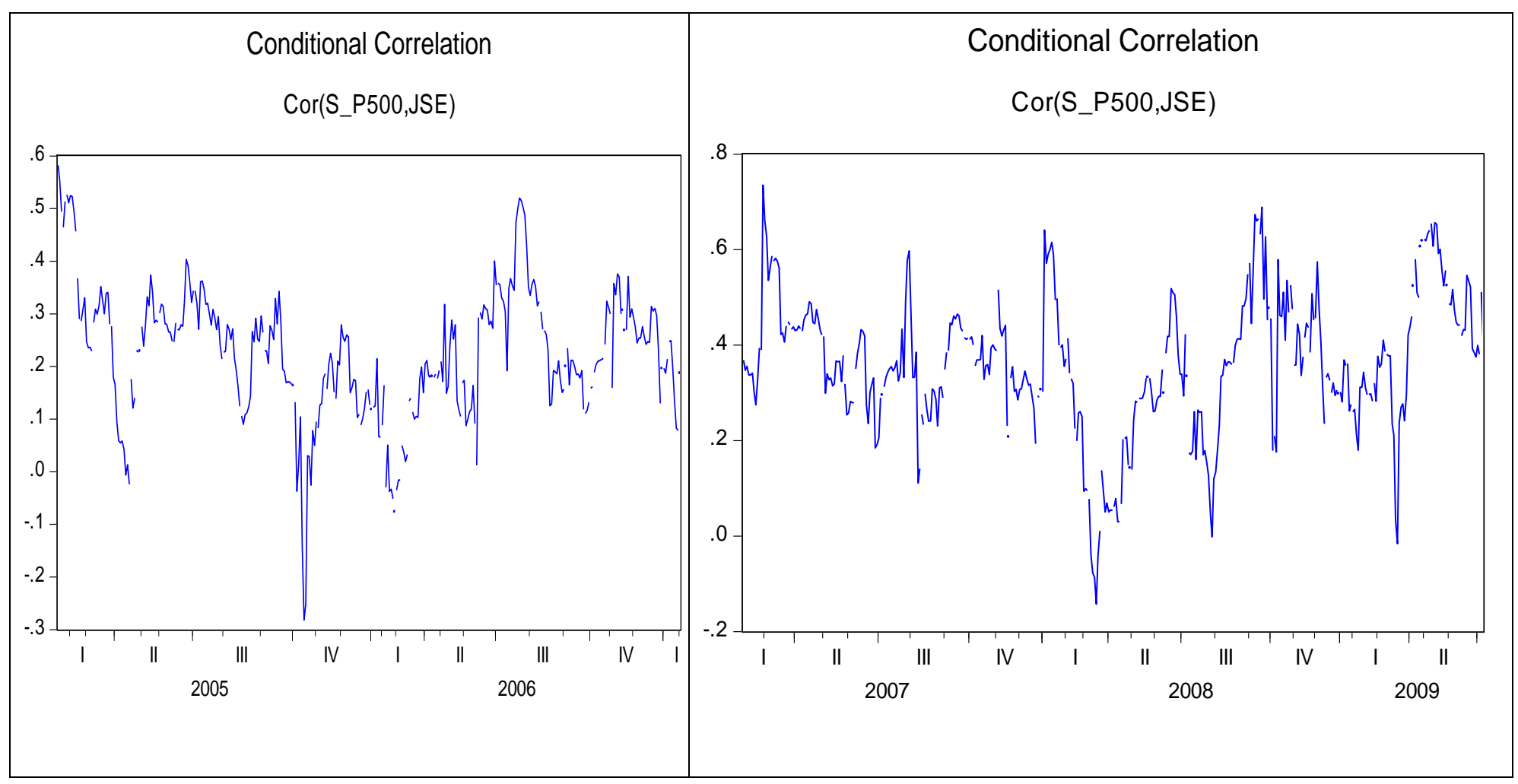

Figure 14. Conditional Correlation using Diagonal VECH GARCH under Student's t- distribution, for 'Pre-crisis' Period (left) and 'Crisis' Period (right) where S\&P500 represents the U.S. Stock Market, and FTSE/JSE represents the South African Stock Market 


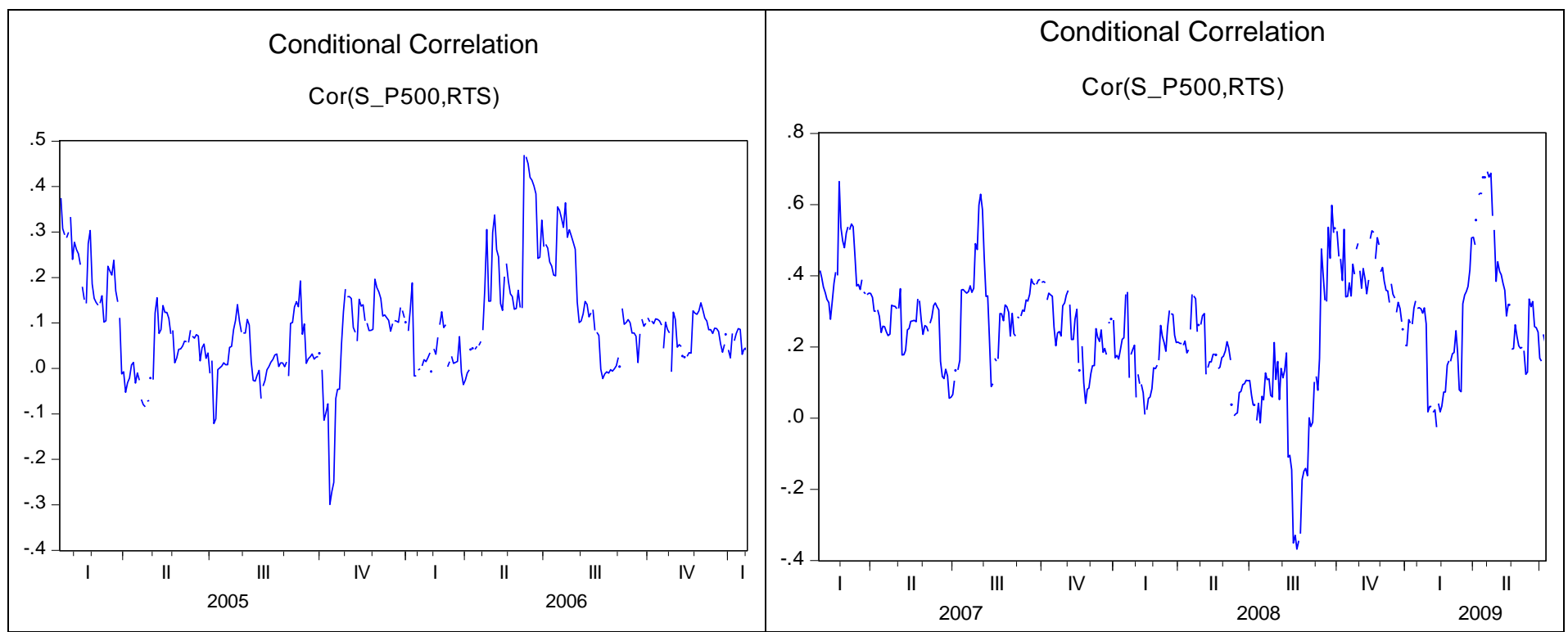

Figure 15. Conditional Correlation using Diagonal VECH GARCH under Student's t-distribution, for 'Pre-crisis' Period (left) and 'Crisis' Period (right) where S\&P500 represents the U.S. Stock Market, and RTS represents the Russian Stock Market

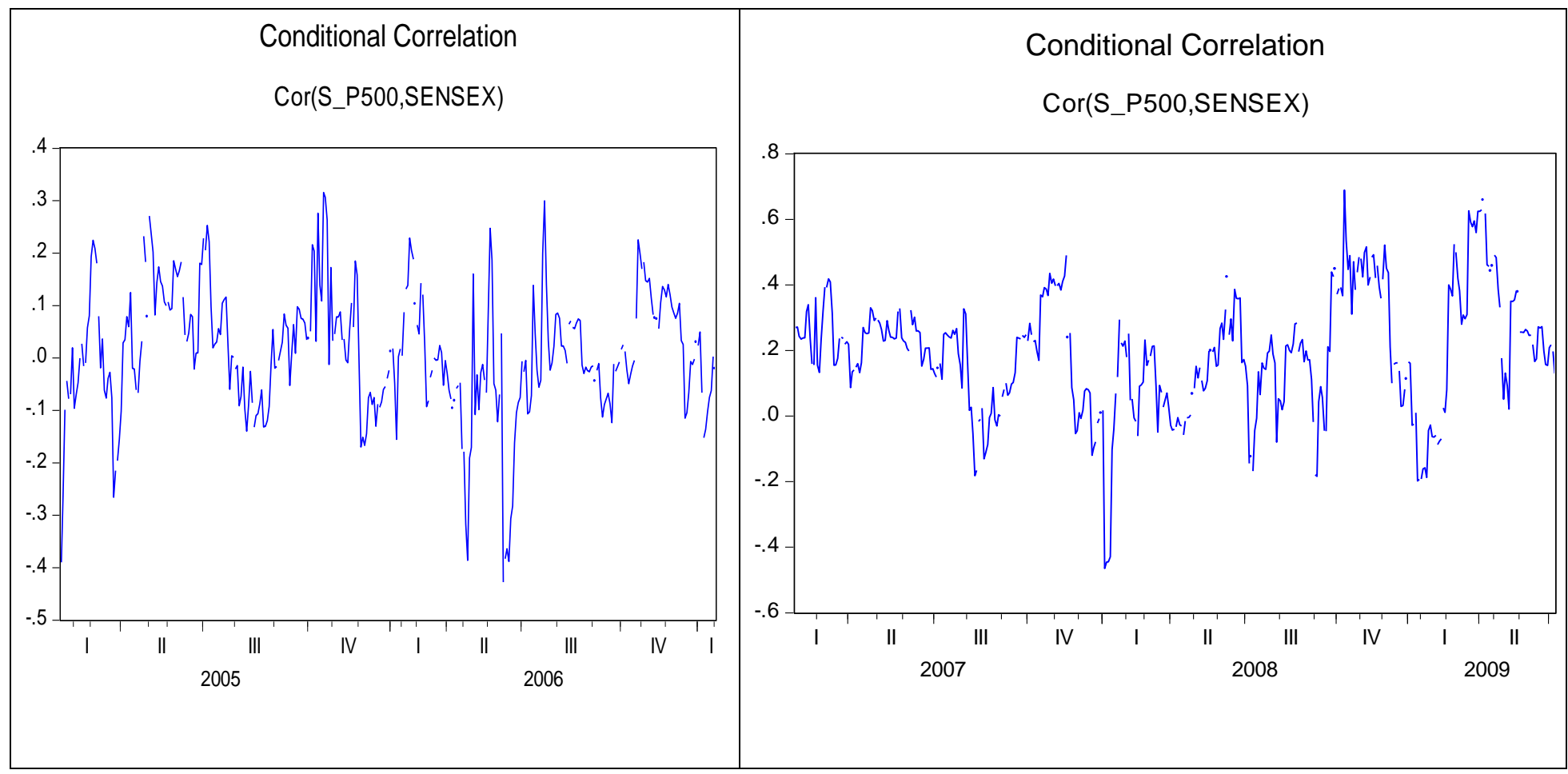

Figure 16. Conditional Correlation using Diagonal VECH GARCH under Student's t-distribution, for 'pre-crisis' Period (left) and 'crisis' Period (right) where S\&P500 represents the U.S. Stock Market, and SENSEX represents the Indian Stock Market 


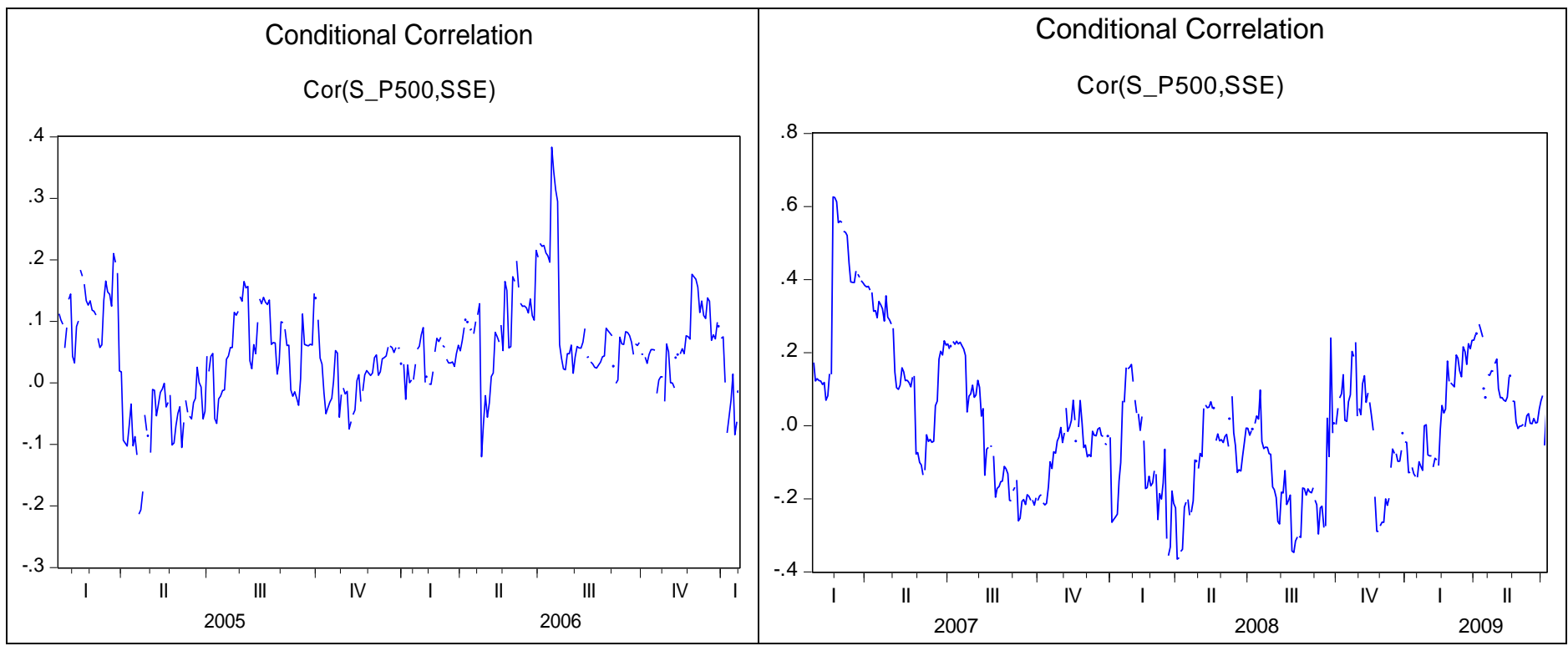

Figure 17. Conditional Correlation using Diagonal VECH GARCH under Student's t-distribution, for 'Pre-crisis' Period (left) and 'Crisis' Period (right) where S\&P500 represents the U.S. Stock Market, and SSE represents the

Chinese Stock Market

\subsection{Diagonal VECH GARCH Estimation for Financial Contagion Following the Eurozone Crisis}

In order to analyse volatility spillover in BRICS equity markets emanating from the Eurozone, the current study uses two sub-periods, namely: (i) the 'crisis' (turmoil) sub-period which spans from $12^{\text {th }}$ August 2009 to $31^{\text {st }}$ December 2012 and (ii) 'the post-crisis' (Note 3) (stable) sub-period that starts on $1^{\text {st }}$ January 2013 and ends on $28^{\text {th }}$ February 2017 in the aftermath of the Eurozone sovereign debt crisis. The present study estimates coefficients for mean equation $\left(\mu_{11}\right.$ and $\left.\mu_{22}\right)$ and the diagonal (bivariate) VECH GARCH model $\left(c_{11}, c_{22}, c_{12}, \alpha_{11}, \alpha_{22}, \alpha_{12}, \beta_{11}, \beta_{22}, \beta_{12}\right)$. The results are presented in Tables 7 and 8 for the present the 'crisis' and 'post-crisis' periods, respectively.

Table 7. Parameter Estimation for Bivariate Diagonal VECH $(1,1)$ Equation for Conditional Correlation with the Eurozone Stock Market in Crisis Period

\begin{tabular}{|c|c|c|c|c|c|c|c|c|c|c|c|c|c|c|}
\hline Parameter & & $\mu_{11}$ & $\boldsymbol{\mu}_{22}$ & $\mathrm{c}_{11}$ & $c_{22}$ & $c_{12}$ & $\alpha_{11}$ & $\alpha_{22}$ & $\alpha_{12}$ & $\beta_{11}$ & $\beta_{22}$ & $\beta_{12}$ & $\begin{array}{l}\text { Student } \\
-t\end{array}$ & L. Likelihood \\
\hline DAX/ & Estimate & 0.066810 & 0.052544 & 0.097419 & 0.253479 & 0.095947 & 0.076157 & 0.054777 & 0.064589 & 0.871354 & 0.821413 & 0.846015 & 8.218655 & -1953.333 \\
\hline \multicolumn{15}{|l|}{ BOVEPA } \\
\hline & SE & 0.050830 & 0.054954 & 0.041500 & 0.110876 & 0.037263 & 0.022737 & 0.01552 & 0.01754 & 0.038173 & 0.064149 & 0.041297 & 2.087305 & \\
\hline & p-value & 0.1887 & 0.3390 & 0.0189 & 0.0008 & 0.0100 & 0.0008 & 0.0051 & 0.0003 & 0.0000 & 0.0000 & 0.0000 & 0.0001 & \\
\hline \multirow[t]{3}{*}{ DAX /JSE } & Estimate & 0.063361 & 0.081137 & 0.057972 & 0.076777 & 0.048240 & 0.111699 & 0.096834 & 0.104002 & 0.880954 & 0.889182 & 0.885058 & 8.883959 & -1459.055 \\
\hline & SE & 0.063256 & 0.071215 & 0.022156 & 0.036770 & 0.019360 & 0.027016 & 0.029102 & 0.024373 & 0.024463 & 0.029311 & 0.022567 & 2.262781 & \\
\hline & p-value & 0.3165 & 0.2546 & 0.0089 & 0.0368 & 0.0127 & 0.0000 & 0.0009 & 0.0000 & 0.0000 & 0.0000 & 0.0000 & 0.0001 & \\
\hline \multirow[t]{3}{*}{ DAX /RTS } & Estimate & 0.081338 & 0.102485 & 0.065919 & 0.155161 & 0.071201 & 0.069977 & 0.049633 & 0.058934 & 0.898794 & 0.903493 & 0.901140 & 6.268179 & -2029.674 \\
\hline & SE & 0.049496 & 0.067109 & 0.030254 & 0.074546 & 0.029206 & 0.019620 & 0.015118 & 0.015264 & 0.026556 & 0.031346 & 0.024678 & 1.152527 & \\
\hline & p-value & 0.1003 & 0.1267 & 0.0293 & 0.0374 & 0.0148 & 0.0004 & 0.0010 & 0.0001 & 0.0000 & 0.0000 & 0.0000 & 0.0000 & \\
\hline \multirow{3}{*}{$\begin{array}{l}\text { DAX } \\
\text { /SENSEX }\end{array}$} & Estimate & 0.078270 & 0.039535 & 0.097106 & 0.043656 & 0.02287 & 0.114136 & 0.037585 & 0.065496 & 0.812331 & 0.929702 & 0.869037 & 7.540683 & -1807.477 \\
\hline & & & & & & & & & & & & & & \\
\hline & SE & 0.04699 & 0.043267 & 0.036982 & 0.023862 & 0.010639 & 0.032177 & 0.015393 & 0.016499 & 0.047358 & 0.025252 & 0.027730 & 1.592480 & \\
\hline
\end{tabular}




\begin{tabular}{|c|c|c|c|c|c|c|c|c|c|c|c|c|c|c|}
\hline & p-value & 0.0545 & 0.3609 & 0.0086 & 0.0673 & 0.0316 & 0.0004 & 0.0146 & 0.0001 & 0.0000 & 0.0000 & 0.0000 & 0.0000 & \\
\hline \multirow[t]{4}{*}{ DAX /SSE } & Estimate & 0.085838 & -0.04678 & 0.088465 & 0.017919 & 0.011198 & 0.128175 & 0.017568 & 0.047453 & 0.809145 & 0.971172 & 0.886465 & 7.446793 & -1917.283 \\
\hline & & & 7 & & & & & & & & & & & \\
\hline & SE & 0.040298 & 0.049926 & 0.036232 & 0.013046 & 0.008470 & 0.037237 & 0.007137 & 0.011938 & 0.049582 & 0.012098 & 0.027671 & 0.049582 & \\
\hline & p-value & 0.0332 & 0.3487 & 0.0146 & 0.1696 & 0.1862 & 0.0006 & 0.0138 & 0.0001 & 0.0000 & 0.0000 & 0.0000 & 0.0000 & \\
\hline
\end{tabular}

Source: Estimation.

Table 8. Parameter Estimation for Bivariate Diagonal VECH $(1,1)$ Equation for Conditional Correlation with the Eurozone in Post-crisis period

\begin{tabular}{|c|c|c|c|c|c|c|c|c|c|c|c|c|c|c|}
\hline Parameter & & $\mu_{11}$ & $\mu_{22}$ & $\mathrm{c}_{11}$ & $c_{22}$ & $c_{12}$ & $\alpha_{11}$ & $\boldsymbol{a}_{22}$ & $a_{12}$ & $\beta_{11}$ & $\boldsymbol{\beta}_{22}$ & $\beta_{12}$ & $\begin{array}{l}\text { Student } \\
-t\end{array}$ & $\begin{array}{l}\text { L. } \\
\text { Likelihood }\end{array}$ \\
\hline \multirow[t]{3}{*}{ DAX/BOVEPA } & Estimate & 0.109272 & 0.043049 & 0.047988 & 0.094356 & 0.024293 & 0.106259 & 0.044362 & 0.068658 & 0.865167 & 0.918073 & 0.891228 & 9.268349 & -2358.328 \\
\hline & SE & 0.037919 & 0.051922 & 0.017786 & 0.042670 & 0.010068 & 0.023055 & 0.015076 & 0.014647 & 0.026251 & 0.027705 & 0.020426 & 2.325470 & \\
\hline & p-value & 0.0040 & 0.4070 & 0.00070 & 0.0270 & 0.0158 & 0.0000 & 0.0033 & 0.0000 & 0.0000 & 0.0000 & 0.0000 & 0.0001 & \\
\hline \multirow[t]{3}{*}{ DAX /JSE } & Estimate & 0.100010 & 0.059076 & 0.037181 & 0.062585 & 0.027318 & 0.064988 & 0.087331 & 0.075336 & 0.908764 & 0.847838 & 0.877772 & 8.201100 & -1920.380 \\
\hline & $\mathbf{S E}$ & 0.037409 & 0.032258 & 0.012287 & 0.026229 & 0.011174 & 0.015252 & 0.023097 & 0.015679 & 0.018607 & 0.041757 & 0.025547 & 1.749412 & \\
\hline & p-value & 0.0075 & 0.0670 & 0.0025 & 0.0170 & 0.0145 & 0.0000 & 0.0002 & 0.0000 & 0.0000 & 0.0000 & 0.0000 & 0.0000 & \\
\hline \multirow[t]{3}{*}{ DAX /RTS } & Estimate & 0.104892 & -0.040603 & 0.038201 & 0.055345 & 0.021443 & 0.073532 & 0.078011 & 0.075738 & 0.903534 & 0.911427 & 0.907472 & 6.983685 & -2390.427 \\
\hline & SE & 0.037887 & 0.055814 & 0.014419 & 0.030046 & 0.010536 & 0.018818 & 0.017446 & 0.014440 & 0.021212 & 0.020576 & 0.020576 & 1.446665 & \\
\hline & p-value & 0.0056 & 0.4669 & 0.0081 & 0.0655 & 0.0418 & 0.0001 & 0.0000 & 0.0000 & 0.00000 & 0.0000 & 0.0000 & 0.0000 & \\
\hline \multirow[t]{3}{*}{ DAX /SENSEX } & Estimate & 0.108081 & 0.066879 & 0.05097 & 0.02768 & 0.015027 & 0.095838 & 0.026721 & 0.050605 & 0.873209 & 0.873209 & 0.909502 & 6.149525 & -2001.283 \\
\hline & $\mathbf{S E}$ & 0.036270 & 0.032699 & 0.019487 & 0.022457 & 0.007093 & 0.025053 & 0.011575 & 0.014352 & 0.028834 & 0.028834 & 0.022518 & 0.969268 & \\
\hline & p-value & 0.0029 & 0.0408 & 0.0089 & 0.2701 & 0.0341 & 0.0004 & 0.0210 & 0.0004 & 0.0000 & 0.0000 & 0.0000 & 0.0000 & \\
\hline \multirow[t]{3}{*}{ DAX / SSE } & Estimate & 0.115362 & 0.048582 & 0.033010 & 0.032539 & 0.000459 & 0.057169 & 0.077573 & 0.066594 & 0.929769 & 0.908598 & 0.919123 & 4.510778 & -2287.868 \\
\hline & $\mathbf{S E}$ & 0.036446 & 0.036974 & 0.16333 & 0.013573 & 0.004902 & 0.019068 & 0.018124 & 0.014658 & 0.020778 & 0.017077 & 0.013969 & 0.623279 & \\
\hline & p-value & 0.0015 & 0.1889 & 0.0433 & 0.0165 & 0.9254 & 0.0027 & 0.0000 & 0.00000 & 0.0000 & 0.00000 & 0.0000 & 0.0000 & \\
\hline
\end{tabular}

Source: Estimation.

From Table 7, it can be seen that during the 'crisis' period, the own-mean spillover coefficients in all BRICS markets $\left(\mu_{22}\right)$ and Eurozone stock market $\left(\mu_{11}\right)$ are not significant and hence inconclusive. For the 'crisis' period parameter estimates $\alpha_{22}$ and $\alpha_{11}$, indicating ARCH effects, are all significant and have a p-value $<0.05$. This indicates the presence of ARCH effects in BRICS and Eurozone stock markets. Parameter estimates $\alpha_{12}$ indicate cross-innovation spillover between the Eurozone and individual BRICS stock markets. Table 7 shows that during the Eurozone sovereign debt crisis, all cross-innovation spillover coefficients were significant with a p-value $<0.01$ and their magnitudes are higher compared to own innovation spillover coefficients $\alpha_{22}$. The strongest $\alpha_{12}$ coefficient is found in South Africa (0.104002), while the weakest is recorded in China (0.047453). Based on the magnitudes of the estimated cross-volatility coefficients, innovation in all of the BRICS stock indices is influenced by the instability of the European stock market, with the cross-volatility shocks being relatively bigger than the own-volatility shocks.

During the 'crisis' period, the coefficient for own conditional volatility (GARCH effect) $\left(\beta_{22}\right)$ is significant at all levels. The largest value is 0.971172 (China), while the lowest is 0.824143 (India). This indicates the persistence of volatility in all BRICS stock market returns.

The cross- conditional volatility coefficients $\left(\beta_{12}\right)$ for the 'crisis' period are significant and are slightly lower in magnitude compared to the $\beta_{22}$ coefficients. The highest $\beta_{12}$ is found in Russia (0.901140) while the lowest is in India (0.846015). Low $\beta_{12}$ estimates compared to $\beta_{22}$ implies that precedent shocks occurring from the Eurozone markets have less impact on BRICS stock markets than own lagged market volatility. 
Table 8 presents results from the 'post-crisis' period. It can be seen that ARCH effects as expressed by coefficient estimate $\alpha_{22}$ are significant at the $1 \%$ level and seem to be slightly lower in magnitude compared to the cross-volatility coefficient $\alpha_{12}$ (except for Brazil and India). The highest ARCH effects are recorded for South Africa (0.08733) and the lowest for China (0.026721). The cross-innovation spill over volatility coefficient for the 'post-crisis' period $\alpha_{12}$ ranges between 0.050605 (India) and 0.075738 (Russia). Similarly, the GARCH effect as expressed by $\beta_{22}$ coefficients is lower compared to cross- conditional volatility coefficient $\beta_{12}$ in the case of South Africa, India and China, suggesting that precedent shocks occurring from the Eurozone market have a greater impact on BRICS stock markets than own lagged market volatility.

Figures 18 to 22 present conditional variances and covariance plots by diagonal VECH GARCH for both the 'crisis' and the 'post-crisis' periods, following the Eurozone sovereign debt crisis. The conditional covariance plots do not show major differences in conditional variance and covariance for the 'crisis' period compared to the 'post-crisis', except for the Chinese stock market. Hence the conclusion that during the Eurozone sovereign debt crisis financial contagion did not take place in the BRICS stock markets. The above results are in line with the Aizenman, Jinjarak, Lee and Park (2016) study, which noted that the effects of Eurozone crisis shocks on emerging countries was mixed and limited during the period 2005 to 2011. However, they cautioned that it would be a mistake for one to assume that there was a decoupling of emerging countries from the Eurozone crisis. The authors posited that, unlike the massive financial contraction triggered by the collapse of Lehman Brothers, the Eurozone crisis had evolved at a slower pace, and thus making it harder to identify the ultimate adverse effects of a deep Eurozone crisis on emerging countries at times of heightened financial instability.

It should also be noted that in Figures 23 to 27 for all stock markets, with the exception of the Chinese market, the conditional correlation reached the highest in the $2^{\text {nd }}$ quarter of 2011 - a period that coincided with the deepening of the Eurozone crisis with the bailout of Portugal, a second bailout for Greece and adoption of austerity measures for Italy.

In Tables 7 and 8, the student's t-distribution and Log-likelihood are also presented. This Student-t test has a coefficient estimated for the degrees of freedom of the distribution. The coefficients of student's t-distribution are statistically significant at $1 \%$ and are between 6 and 14. One should also note that for having a defined variance, the degrees of freedom have to be greater than 2 , hence the conclusion that with the diagonal VECH model, the variance is well defined. Additionally, as we know, the Student's t distribution tends towards the normal distribution when we consider infinite degrees of freedom. Having such small figures (although still well defined, as mentioned before) leads the author to reason, and confirm, that the data follows a heavy-tailed distribution.

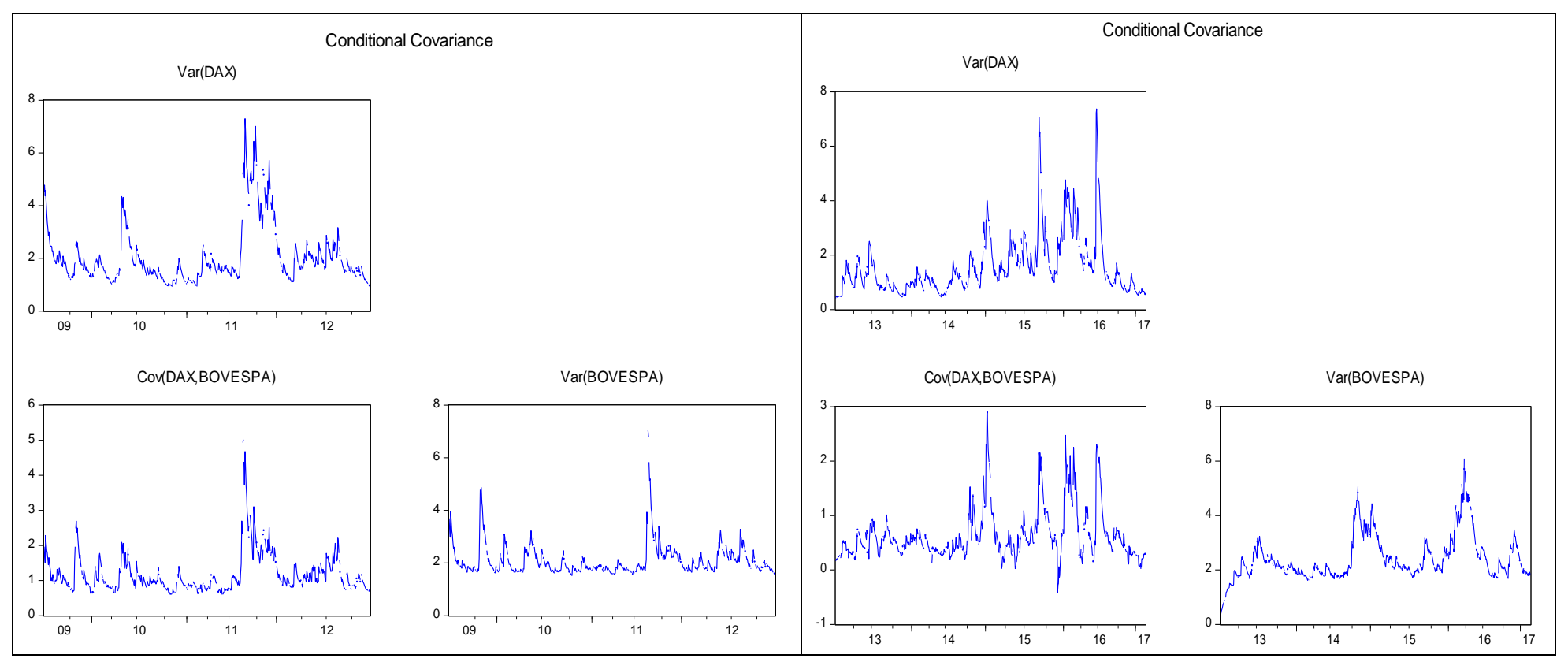

Figure 18. Estimated Conditional Variance and Covariance using Diagonal VECH GARCH under Student's t-distribution, for 'Crisis' Period (left) and 'Post-crisis' Period (right) where DAX represents the Eurozone Stock Market, and BOVESPA represents the Brazilian Stock Market 


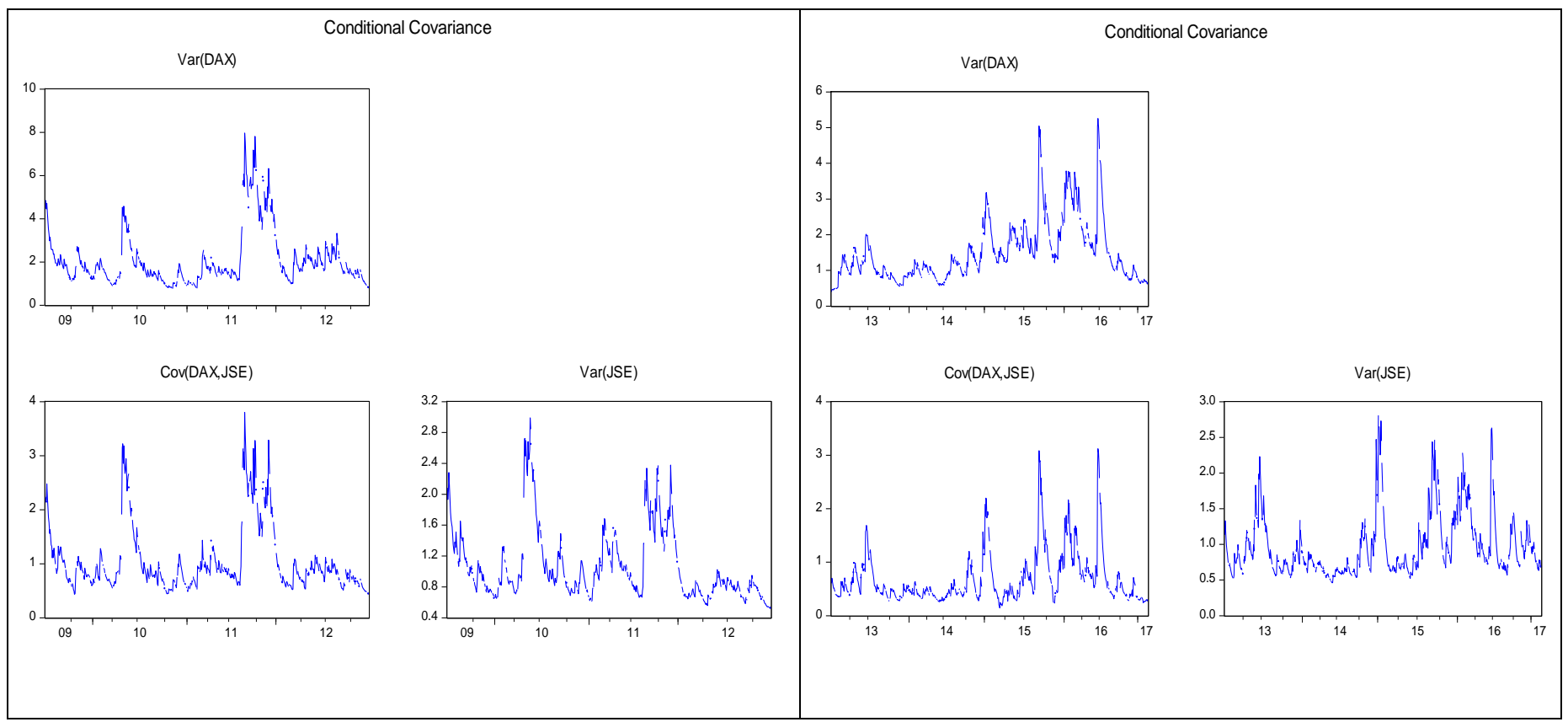

Figure 19. Estimated Conditional Variance and Covariance using Diagonal VECH GARCH under Student's t-distribution, for 'Crisis' Period (left) and 'Post-crisis' Period (right) where DAX represents the Eurozone Stock

Market, and JSE represents the South African Stock Market

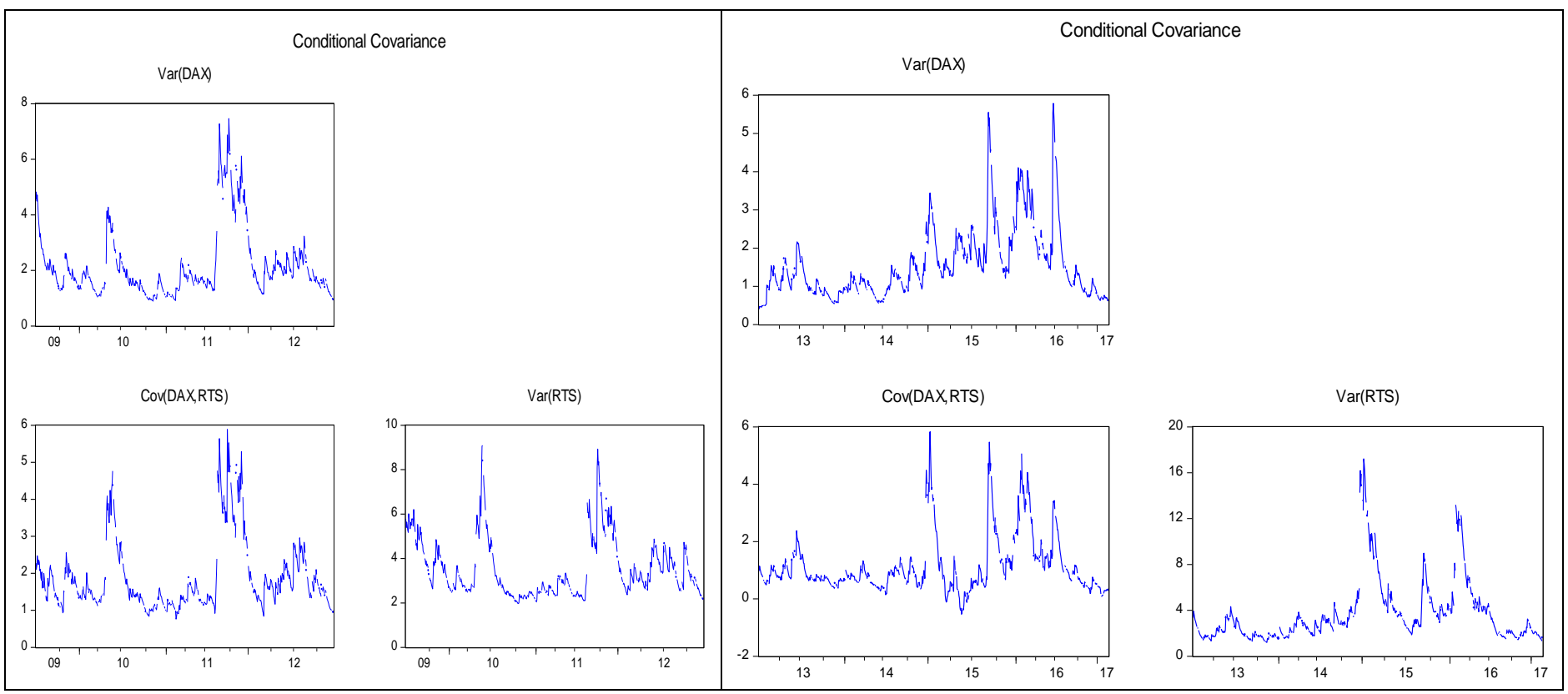

Figure 20. Estimated Conditional Variance and Covariance using Diagonal VECH GARCH under Student's t-distribution, for 'Crisis' Period (left) and 'Post-crisis' Period (right). Where DAX represents the Eurozone Stock Market, and RTS represents the Russian Stock Market 


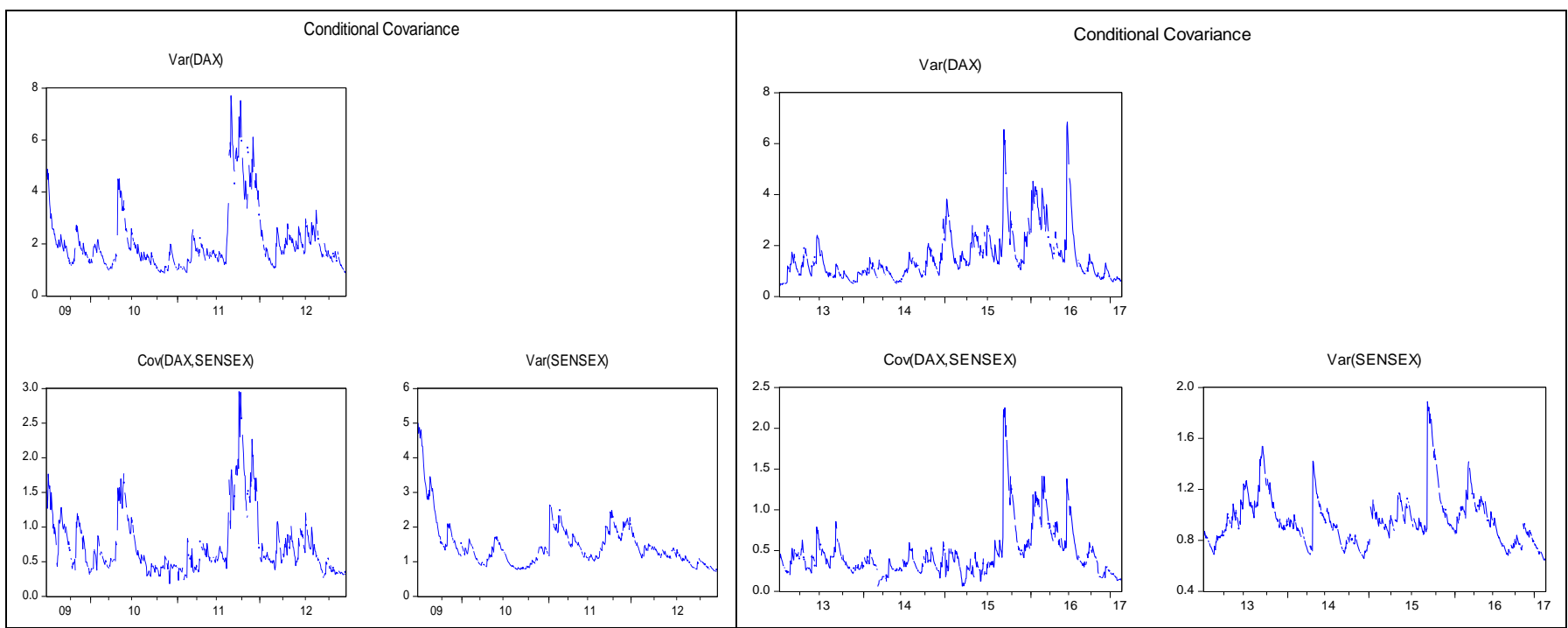

Figure 21. Estimated Conditional Variance and Covariance using Diagonal VECH GARCH under Student's t-distribution, for 'Crisis' Period (left) and 'Post-crisis' Period (right) where DAX represents the Eurozone Stock Market, and SENSEX represents the Indian Stock Market

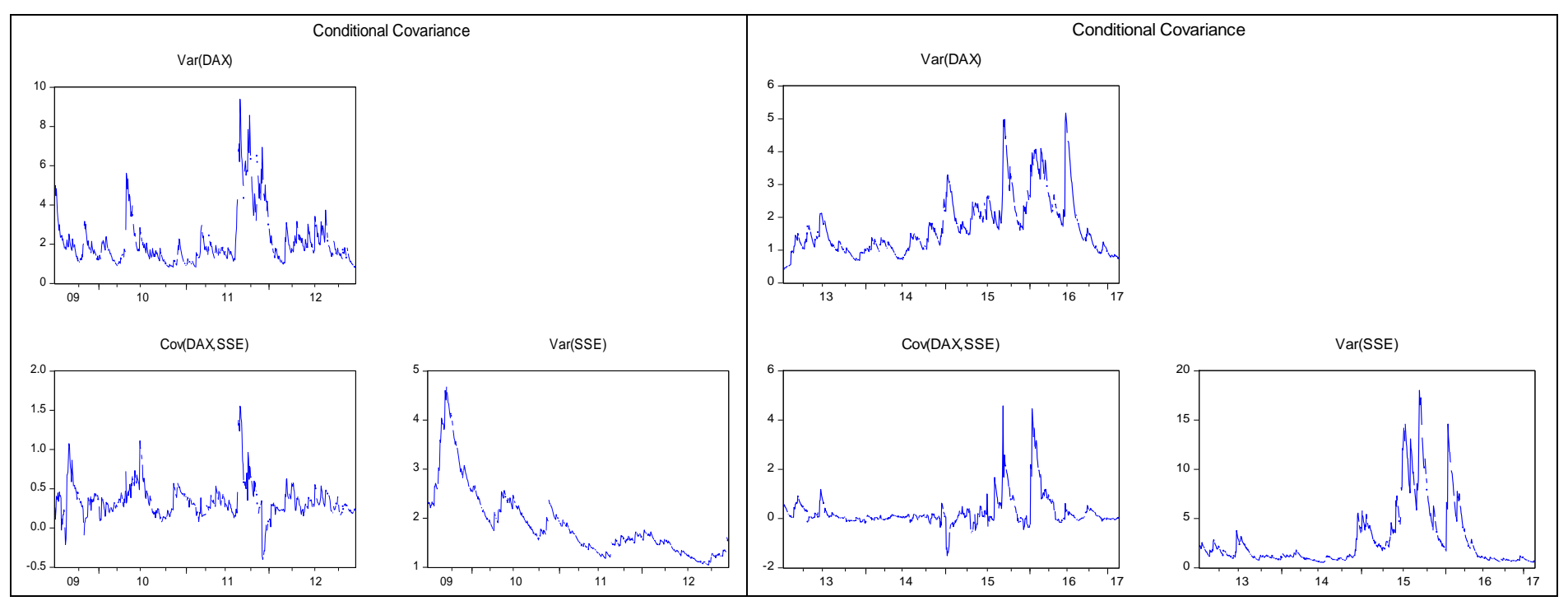

Figure 22. Estimated Conditional Variance and Covariance using Diagonal VECH GARCH under Student's t-distribution, for 'Crisis' Period (left) and 'Post-crisis' Period (right). DAX represents the Eurozone Stock Market, and SSE represents the Chinese Stock Market 


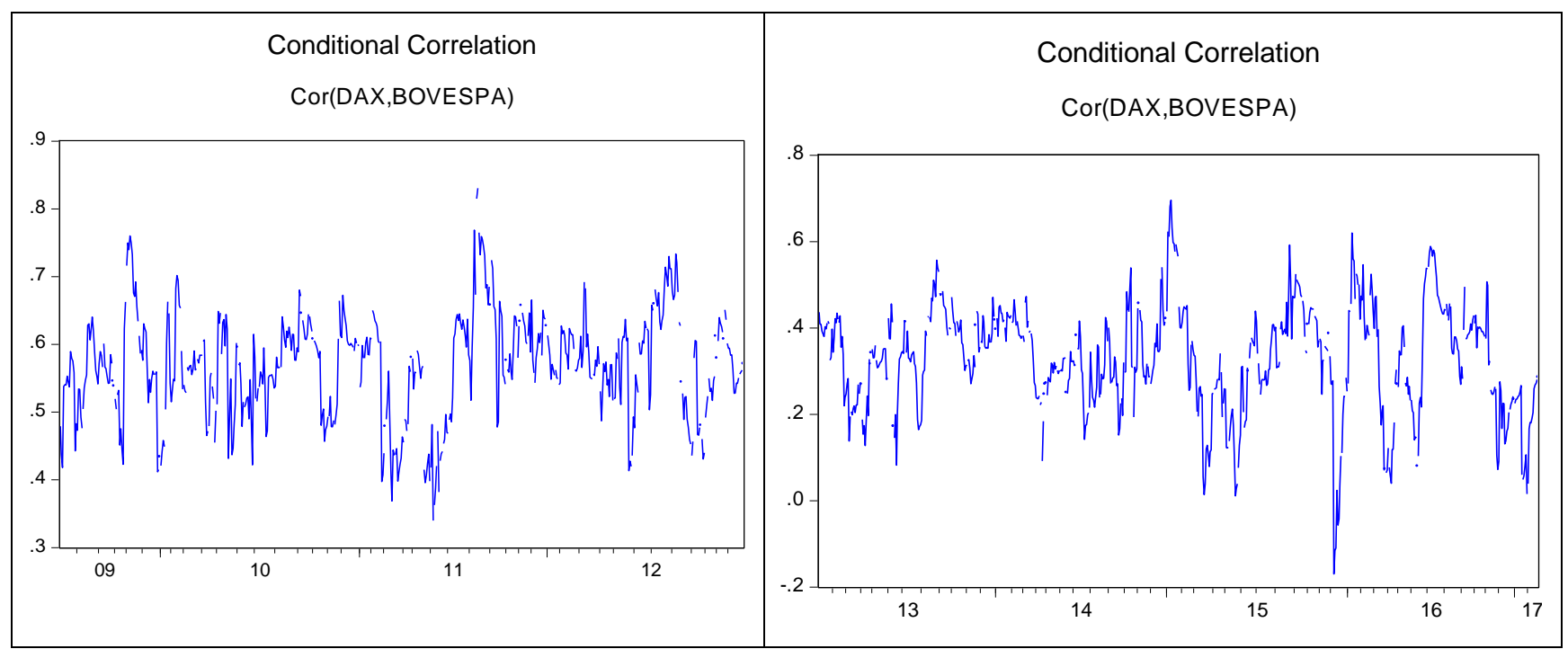

Figure 23. Estimated Conditional Correlation using Diagonal VECH GARCH under Student's t-distribution, for 'Crisis' Period (left) and 'Post-crisis' Period (right) where DAX represents the Eurozone Stock Market, and BOVESPA represents the Brazilian Stock Market

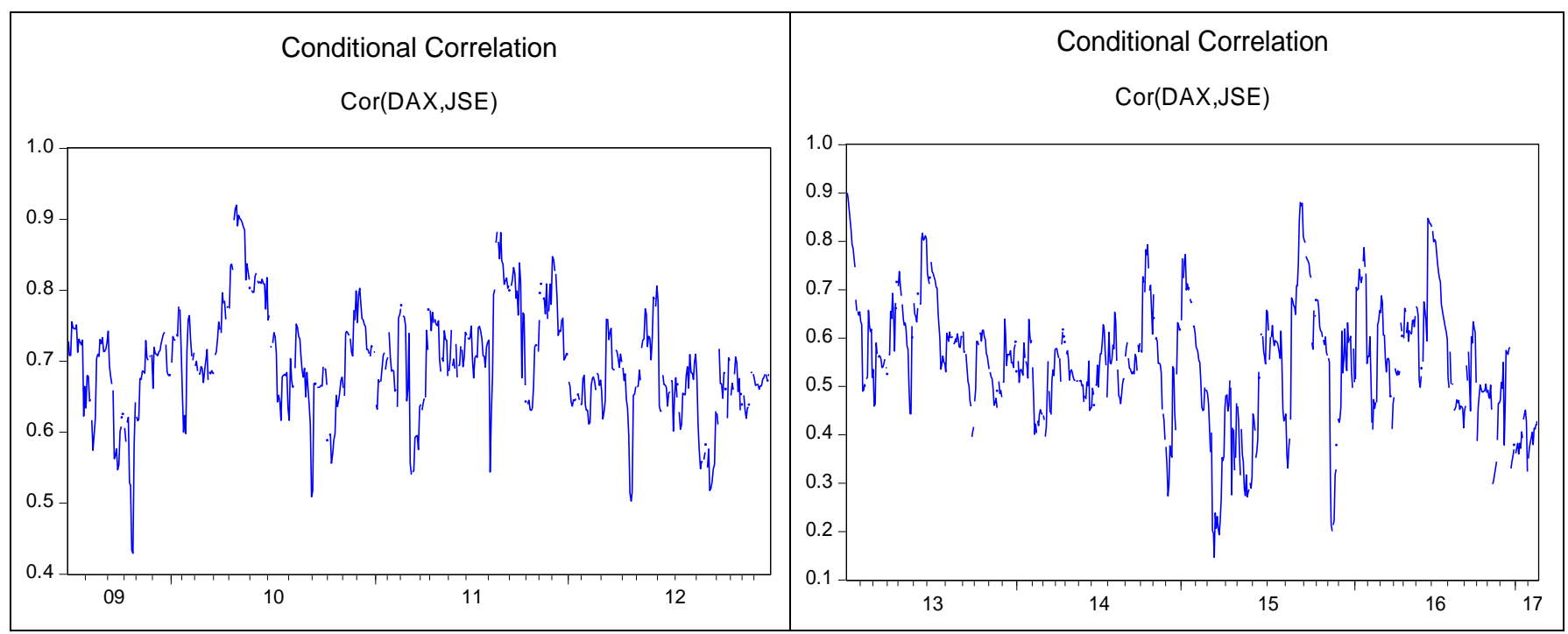

Figure 24. Estimated Conditional Correlation using Diagonal VECH GARCH under Student's t-distribution, for 'crisis' Period (left) and 'post-crisis' Period (right) where DAX represents the Eurozone stock market, and JSE represents the South African Stock Market 


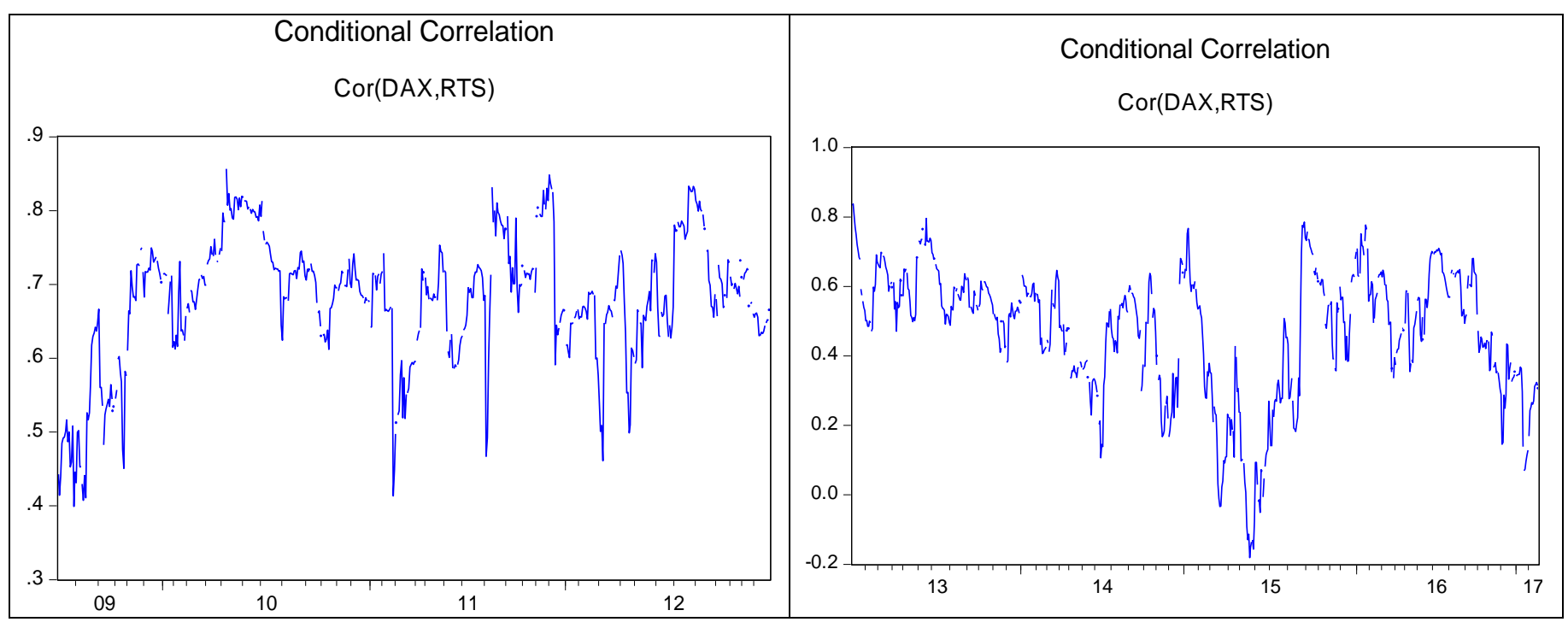

Figure 25. Estimated Conditional Correlation using Diagonal VECH GARCH under Student's t-distribution, for 'Crisis' Period (left) and 'Post-crisis' Period (right) where DAX represents the Eurozone Stock Market, and RTS represents the Russian Stock Market

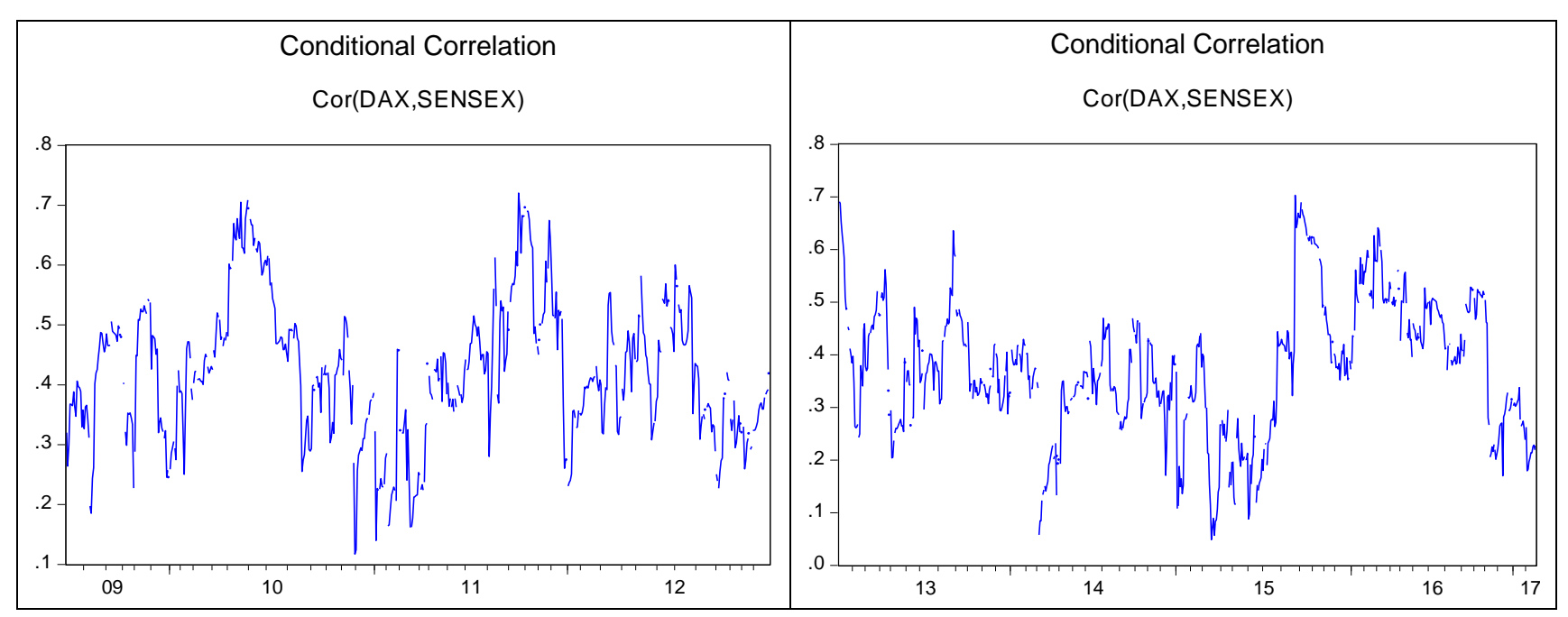

Figure 26. Estimated Conditional Correlation using Diagonal VECH GARCH under Student's t-distribution, for 'Crisis" Period (left) and 'Post-crisis' Period (right) where DAX represents the Eurozone Stock Market, and SENSEX represents the Indian Stock Market 


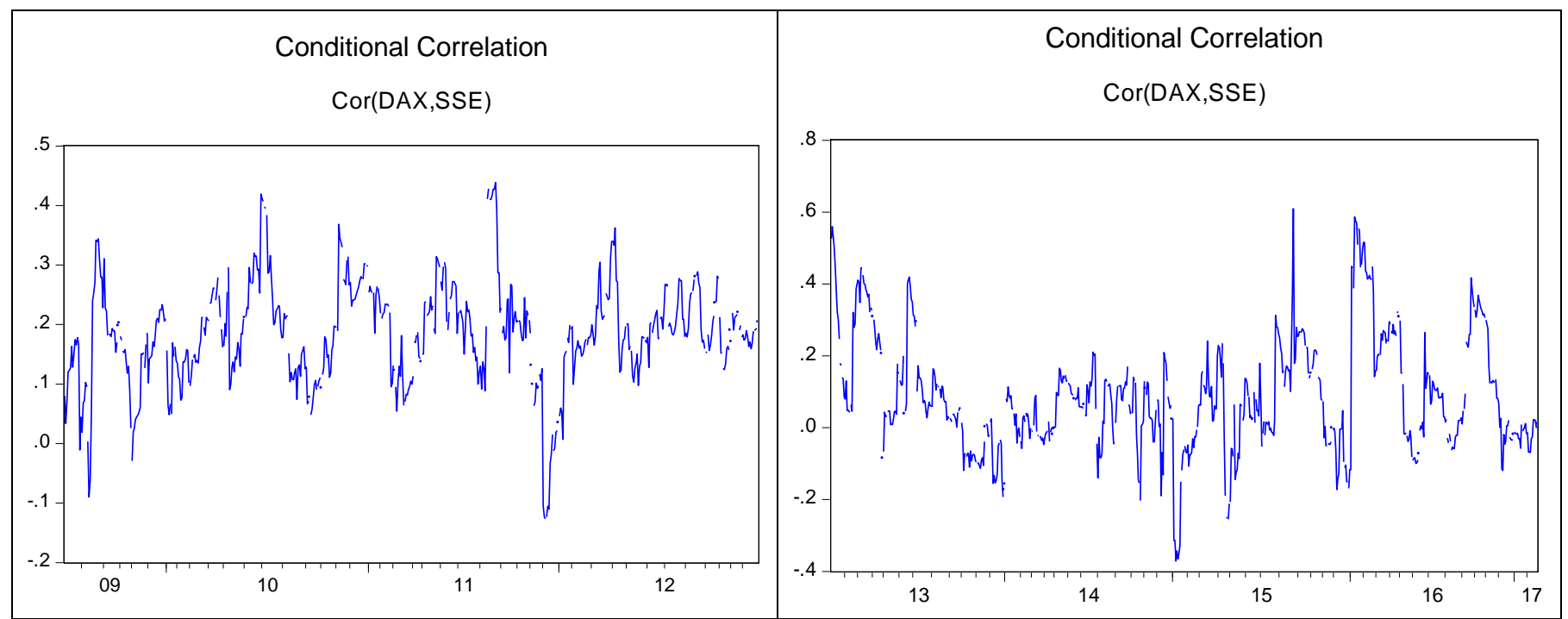

Figure 27. Estimated Conditional Correlation using Diagonal VECH GARCH under Student's t-distribution, for 'Crisis" Period (left) and 'Post-crisis' Period (right). DAX represents the Eurozone Stock Market, and SSE represents the Chinese Stock Market

\subsection{Diagnostic Test for Diagonal VECH GARCH Model}

After fitting the VECH GARCH model, the adequacy specification of the model is assessed. The results of the Box-Ljun statistic on standardised squared residual are presented in Tables 9 and 12 for all periods.

Table 9. Bivariate Box-Ljung Q-statistics for Standardised Squared Residuals with the S\&P500 During the Sub-prime 'Pre-crisis' Period

\begin{tabular}{lllll}
\hline & Q $(12)$ & P-value & Qs(12) & P-value \\
\hline BOVESPA & 54.09565 & 0.2530 & 55.09829 & 0.2240 \\
\hline JSE & $\mathbf{1 2 0 . 0 7 3 8}$ & 0.0000 & $\mathbf{1 2 1 . 3 7 8 4}$ & 0.0000 \\
\hline RTS & $\mathbf{6 1 . 1 1 0 8 3}$ & 0.0000 & $\mathbf{6 1 . 4 0 0 2 7}$ & 0.000 \\
\hline SENSEX & $\mathbf{1 0 7 . 7 3 0 4}$ & 0.0000 & $\mathbf{1 0 9 . 2 4 8 6}$ & 0.000 \\
\hline SEE & 51.52512 & 0.3376 & 52.33589 & 0.3094
\end{tabular}

Source: Estimation.

Table 10. Bivariate Box-Ljung Q-statistics for Standardised Squared Residuals with the S\&P500 During the Sub-prime 'Crisis' Period

\begin{tabular}{lllll}
\hline & Q $(12)$ & P-value & Qs(12) & P-value \\
\hline BOVESPA & $\mathbf{1 4 2 . 8 8 9 2}$ & 0.0000 & $\mathbf{1 4 4 . 9 7 9 2}$ & 0.0000 \\
\hline JSE & $\mathbf{1 6 9 . 9 9 3 3}$ & 0.0000 & $\mathbf{1 7 1 7 . 5 6 6}$ & 0.0000 \\
\hline RTS & $\mathbf{2 0 3 . 8 0 5 5}$ & 0.0000 & $\mathbf{2 0 6 . 5 4 7 6}$ & 0.0000 \\
\hline SENSEX & $\mathbf{1 2 3 . 2 9 8 5}$ & 0.0000 & $\mathbf{1 2 4 . 4 8 0 8}$ & 0.0000 \\
\hline SEE & $\mathbf{9 2 . 9 0 0 7 5}$ & 0.0001 & $\mathbf{9 4 . 1 4 3 1 9 0}$ & 0.0001
\end{tabular}

Source: Estimation. 
Table 11. Bivariate Box-Ljung Q-statistics for Standardised Residuals with the DAX During the 'Crisis' Period

\begin{tabular}{lllll}
\hline & $\mathrm{Q}(12)$ & P-value & $\mathrm{Qs}(12)$ & P-value \\
\hline BOVESPA & $\mathbf{6 9 . 7 9 4 6 3}$ & 0.0216 & $\mathbf{7 0 . 3 5 9 0 2}$ & 0.0194 \\
\hline JSE & 60.89759 & 0.1001 & 61.46634 & 0.0917 \\
\hline RTS & 84.49552 & 0.0009 & $\mathbf{8 5 . 2 6 5 4 5}$ & 0.0007 \\
\hline SENSEX & 79.44678 & 0.0029 & $\mathbf{8 0 . 2 0 4 3 8}$ & 0.0024 \\
\hline SEE & 61.4286 & 0.0923 & 61.94350 & 0.0851 \\
\hline
\end{tabular}

Source: Estimation.

Table 12. Bivariate Box-Ljung Q-statistics for Standardised Residuals with DAX during the 'Post-crisis' Period

\begin{tabular}{lllll}
\hline & $\mathrm{Q}(12)$ & P-value & Qs $(12)$ & P-value \\
\hline BOVESPA & $\mathbf{6 9 . 7 9 4 6 3}$ & 0.0216 & $\mathbf{7 0 . 3 5 9 0 2}$ & 0.0194 \\
\hline JSE & $\mathbf{9 3 . 0 4 7 5 2}$ & 0.0001 & $\mathbf{9 3 . 6 8 7 4 7}$ & $0.000 \mathrm{C}$ \\
\hline RTS & $\mathbf{7 2 . 5 5 5 0 2}$ & 0.0126 & $\mathbf{7 3 . 1 2 2 3 2}$ & 0.0112 \\
\hline SENSEX & $\mathbf{6 8 . 0 9 3 5 8}$ & 0.0297 & $\mathbf{6 8 . 6 2 9 8}$ & 0.0269 \\
\hline SEE & $\mathbf{1 0 2 . 7 3 7 6}$ & 0.0000 & $\mathbf{1 0 0 3 . 5 3 8 3}$ & 0.000 \\
\hline
\end{tabular}

Source: Estimation.

The results in Tables 9 to 12 suggest the existence of serial dependence in the bivariate return series as the p-value for the Q-statistics test is close to zero, hence the rejection of the null hypothesis that there no residual autocorrelation up to lag 12. This suggests that the fitted Diagonal VECH model could not remove the GARCH effect (heteroscedasticity). Attempts by the researcher to modify the model by assuming a normal Gaussian distribution and by estimating the model with asymmetries yielded similar results.

Figures 28 to 31 present autocorrelation and cross-correlation of the standardised residuals and the squared standardised residuals of the series. For some of the lags, the sample ACFs are within the distance between positive and negative 2 times standard deviation lines at 95\% confidence level; this confirms that the diagonal VECH GARCH model did not remove GARCH effects. 

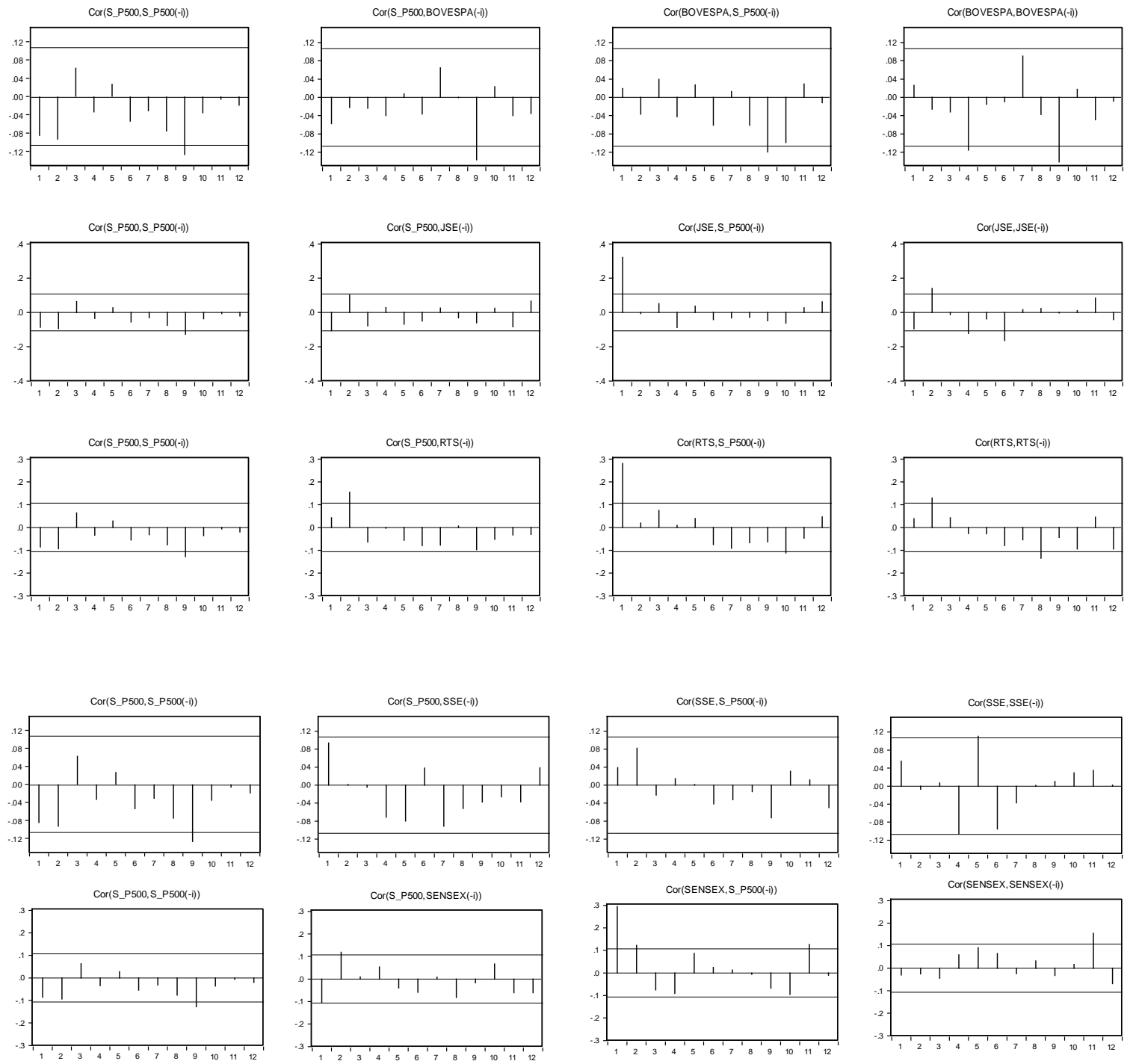

Figure 28. ACFs Standardized Residual of the Diagonal Bivariate VECH Model for the 'Pre-crisis' Period during the Sub-prime Crisis 

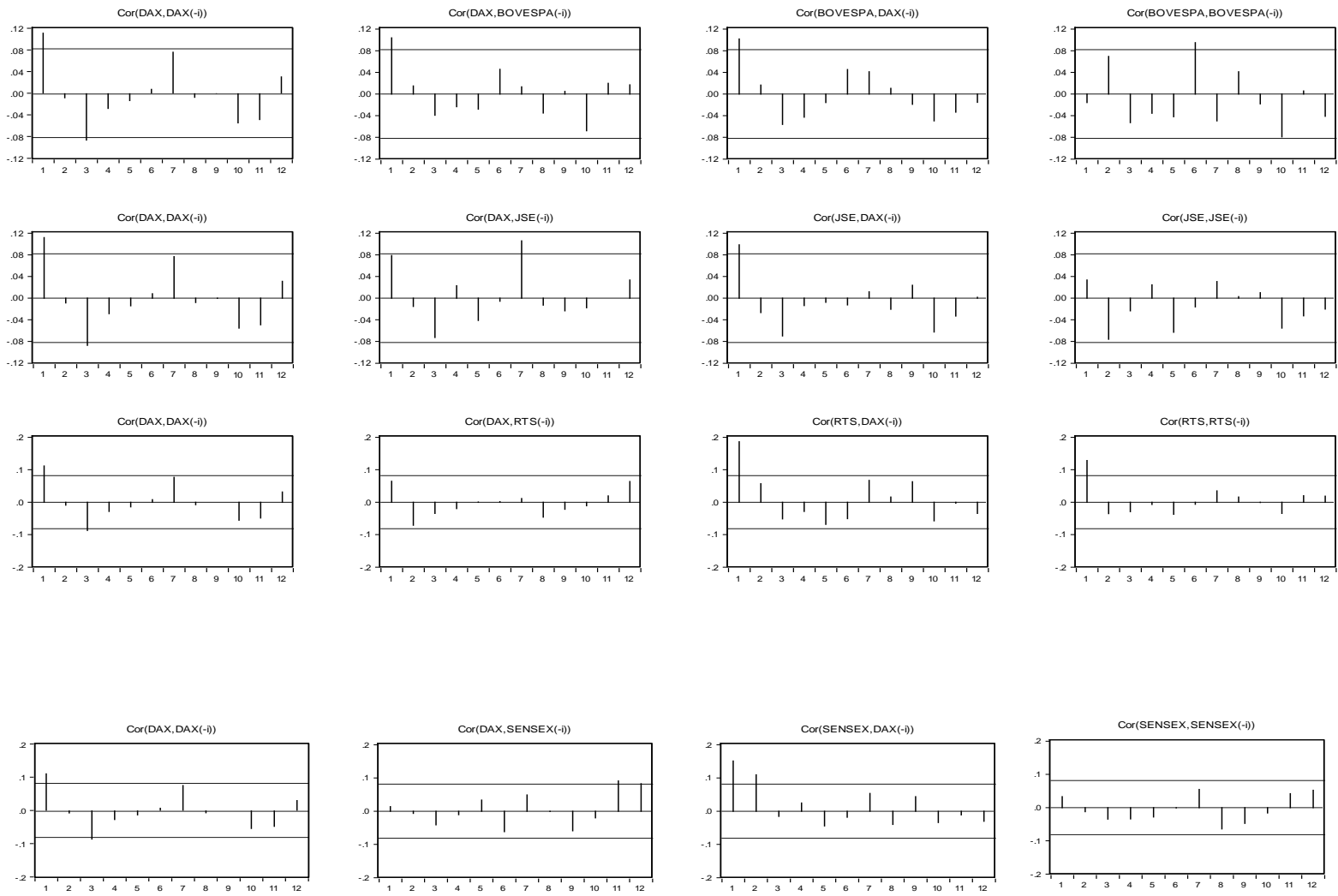

$\operatorname{Cor}(\operatorname{DAX}, \operatorname{DAX}(-\operatorname{m)})$

Cor(DAX,SSE(-1)
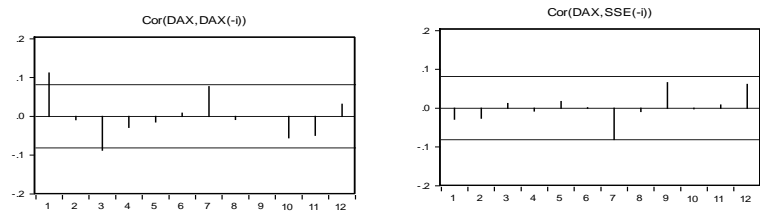

COr(SSE,DAX(--))

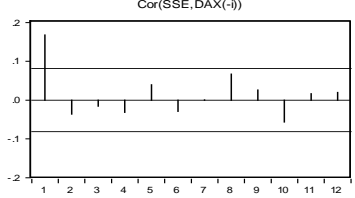

Cor(SSE,SSE(-D))

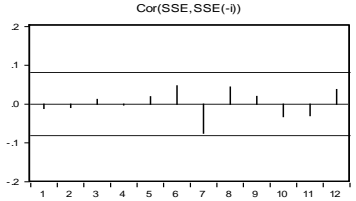

Figure 29. ACFs Standardized Residual of the Diagonal Bivariate VECH Model for the 'Crisis' Period during the Sub-prime Crisis
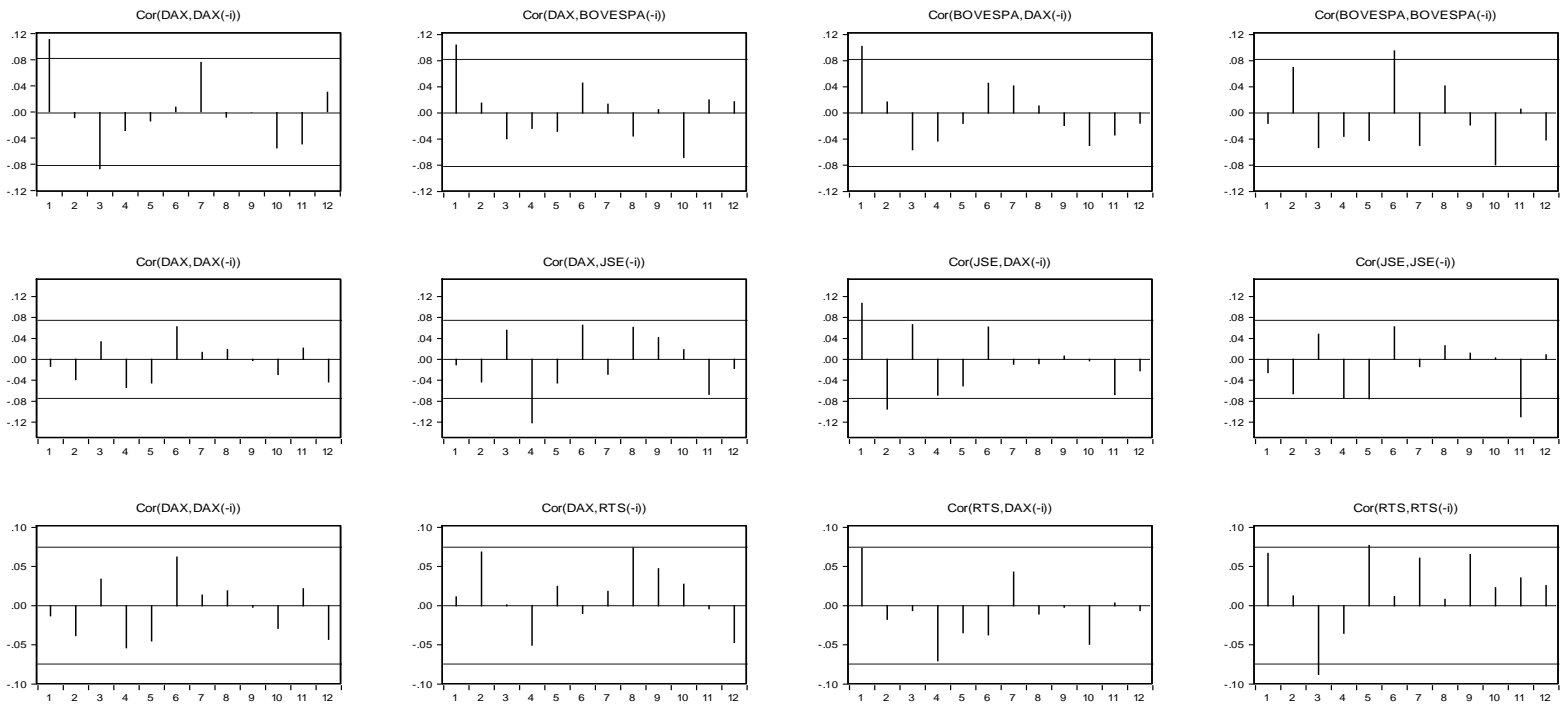


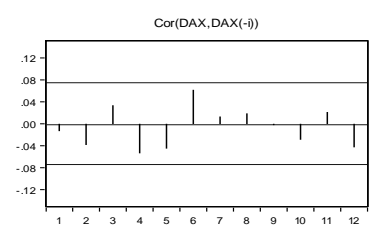

$\operatorname{Cor}(\operatorname{DAX}, \operatorname{DAX}(-\mathrm{i}))$

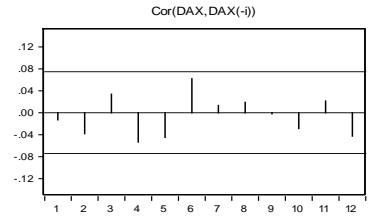

$\operatorname{Cor}($ DAX,SENSEX $(-1))$

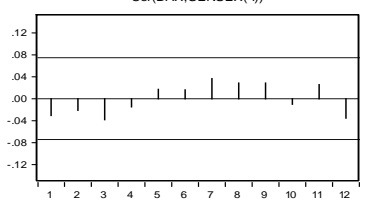

$\operatorname{Cor}(\mathrm{DAX}, \mathrm{SSE}(-\mathrm{i}))$

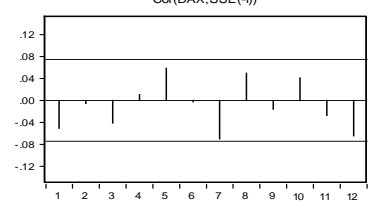

Cor(SENSEX, DAX(-i))

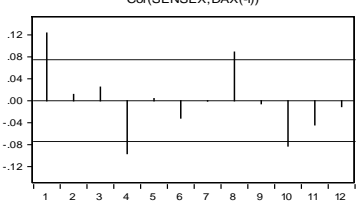

Cor(SSE,DAX(-i))

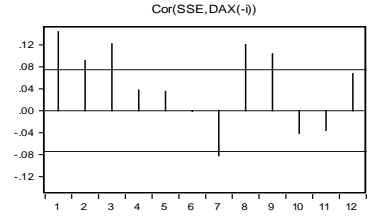

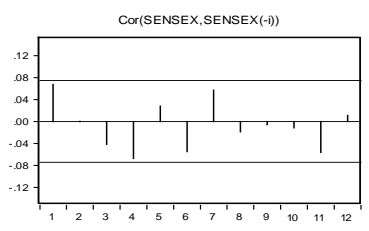

Cor(SSE,SSE(-))

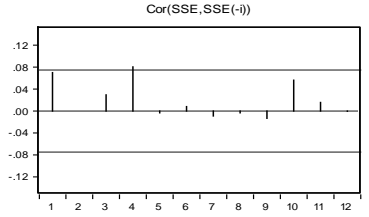

Figure 30. ACFs Standardized Residual of the Diagonal Bivariate VECH Model for the 'Crisis' Period during EZDC

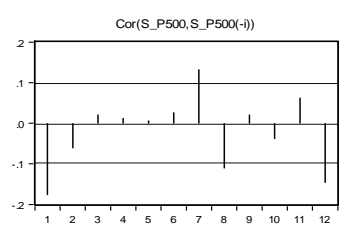

Cor(S_P500,S_P500(-i))

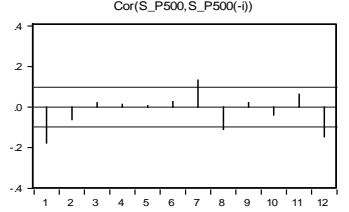

Cor(S_P500,S_P500(-1))

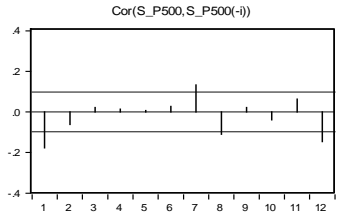

Cor(S_P500,BOVESPA(-D))

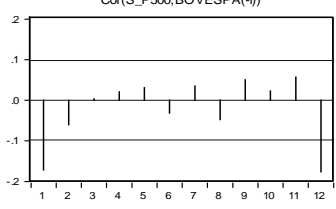

Cor(S_P500,JSE(-1))

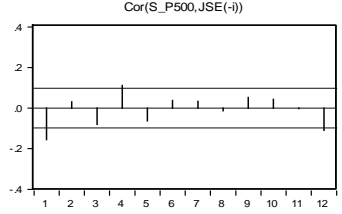

Cor(S_P500,RTS(-i))

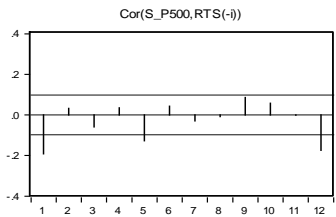

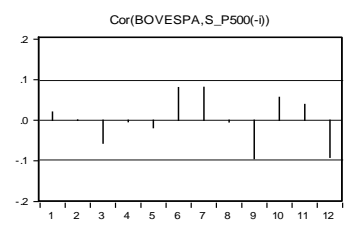

Cor(JSE,S_P500(-i))

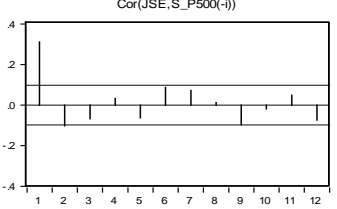

Cor(RTS,S_P500(-i))

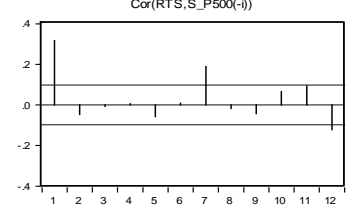

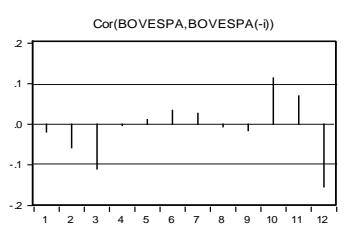

$\operatorname{Cor(JSE,JSE(-1))}$

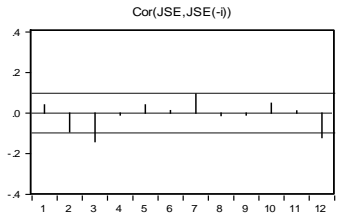

$\operatorname{Cor}($ RTS, RTS $(-1))$

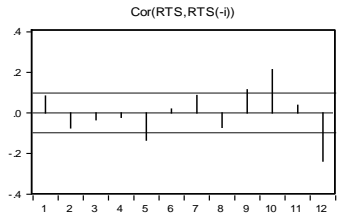

Figure 31. ACFs Standardized Residual of the Diagonal Bivariate VECH Model for the 'Post-crisis' Period during EZDC

It should be drawn to the reader's attention that the diagonal VECH models has drawbacks, among them is the fact that (i) they do not enforce positive definiteness and, (ii) they do not allow for complicated interactions among variables as the spillover effect is precluded by its structure where the only determinant of the variance of one series is its own shocks (Brook, 2014). Furthermore, the DVECH MGARCH models are less parsimonious and offer less flexibility of their specifications for a time-varying conditional covariance matrix of the disturbance. To circumvent these problems, Niyitegeka and Tewari (2021) used the Dynamic Conditional Correlation (DCC) GARCH model as it allows correlations to be time-varying in addition to the conditional variances. Nevertheless, their results were in line with those obtained in the current study.

\section{Conclusion}

This article presented a discussion on the use of multivariate GARCH models to examine the volatility spillover in BRICS countries in the wake of the U.S. sub-prime and the Eurozone sovereign debt crises. For each crisis that data were divided into two periods, (i) the turbulent period and (ii) the stable period. Students' t-distribution Bivariate GARCH models were utilised to examine the dynamic financial contagion between the U.S. as source markets and individual BRICS stock markets as target markets. In this regard, bivariate Diagonal VECH GARCH model were used to estimate the volatility and correlations of the BRICS returns. It was found that there was a presence of 
cross-conditional volatility. The results also showed that the cross-conditional volatility coefficient is high in magnitude during periods of financial upheaval compared to a tranquil period, hence the conclusion that there was financial contagion during the U.S. sub-prime crisis (except in China).

As for the sovereign debt crisis in the Eurozone countries, equity markets in BRICS countries seemed to react equally (in both the 'crisis' and 'post-crisis' periods) from shocks emanating from European equity market. Hence the conclusion that there was no contagion in BRICS countries following the Eurozone sovereign debt crisis.

Diagnostic tests were carried out on the GARCH models to check for the adequacy of the models. The results of the tests showed that the bivariate GARCH models were sufficient for estimating the volatility and conditional correlations of the BRICS returns.

\section{Policy Implications}

Since that financial contagion emanating from the US was detected in BRICS market with the exception of Chinese market, the implications thereof are that firstly policymakers, investors and regulatory authorities should focus more on monitoring the volatility of the U.S. equity market as effort by BRICS authorities to stabilise volatility in their stock markets is futile since the most of the volatility comes from outside.

Secondly, regulatory authorities should come up with initiatives that enable investors to reduce significant risk exposure by formulating sound risk management policies and macroprudential regulations.

Thirdly, BRICS countries should formulate and implement reliable hedging strategies against the contagious effects of the U.S. stock market on BRICS stock markets.

Fourthly, financial liberalisation processes need to be an integral part of the financial restructuring process, given the fact that financial integration can weaken and render vulnerable the emerging economies stock markets, due to their interdependencies with the US market. The strengthening of the requirement for the proper implementation of market liberalisation and the need for gradual deregulation is required.

Lastly, despite governments in BRICS countries taking steps to mitigate contagion-related risks from the U.S. market, there is still evidence of pure contagion in BRICS markets that emanates from the U.S. Additional best practices and tools are needed to address the current fissures. Global measures could include improving risk management and better mechanisms of private and counterparty risk sharing, reduction of systemic risk (for example the use of prudential regulations and the use of very-low risk assets), and the establishment more cautious financing facilities.

Given the fact that the current study could not identify financial contagion in Brazilian, Chinese and Indian stock markets emanating from Eurozone countries, the implication is that policymakers need to pay due attention to idiosyncratic shock channels in responding to volatility spillover.

\section{References}

Aizenman, J., Jinjarak, Y., Lee, M., \& Park, D. (2016). Developing countries' financial vulnerability to the Eurozone crisis: An event study of equity and bond markets. Journal of Economic Policy Reform, 19(1), 1-19.

Bollerslev, T. (1986). Generalized autoregressive conditional heteroskedasticity. Journal of Econometrics, 31, 307-327.

Bollerslev, T., Engle, R. F., \& Wooldridge, J. M. (1988). A capital asset pricing model with time-varying covariances. Journal of Political Economy, 96 (1), 116-131.

Bonga-Bonga, L. (2018). Uncovering equity market contagion among BRICS countries: an application of the multivariate GARCH model. The Quarterly Review of Economics and Finance, 67, 36-44.

Brooks, C. (2014). Introductory econometrics for finance. Cambridge University Press.

Duttagupta, R., \& Pazarbasioglu, C. (2021). Miles to Go. Finance \& development 58, 02. New York: International $\begin{array}{lllll}\text { monetary } & \text { Fund. } & \text { Retrieved } & \text { January } & \text { 2022, }\end{array}$ https://www.elibrary.imf.org/view/journals/022/0058/002/022.0058.issue-002-en.xml

Engle, R. F. (1982). Autoregressive conditional heteroscedasticity with estimates of the variance of United Kingdom inflation. Econometrica: Journal of the Econometric Society, 50(4), 987-1007.

Forbes, K. J., \& Rigobon, R. (2002). No contagion, only interdependence: measuring stock market comovements. The Journal of Finance, 57(5), 2223-2261.

Ithurbide, P., \& Bellaiche, M. (2019). How to differentiate emerging countries? New approaches for classification 
and typology. Amundi Research Team, 3-60.

Koba, M. (2011). BRICS: CNBC Explains. CNBC. Retrieved 9 September 2020, from https://www.cnbc.com/2011/08/11/brics-cnbc-explains.html

$\mathrm{Lu}$ J. (2019). Five reasons for strategic allocation to China A-shares. Robeco website. Retrieved 9 September, 2021, from https://www.robeco.com/za/insights/2019/05/five-reasons-for-strategic-allocation-to-china-a-shares.html

Mohti, W., Dionísio, A., Vieira, I., \& Ferreira, P. (2019). Financial contagion analysis in frontier markets: Evidence from the US subprime and the Eurozone debt crises. Physica A: Statistical Mechanics and its Applications, 525, 1388-1398.

Niyitegeka, O., \& Tewari, D. D. (2021). Bivariate Conditional Heteroscedasticity Model with Dynamic Correlations for Testing Contagion in BRICS Countries. Academy of Accounting and Financial Studies Journal, 25, 1-17.

O’Neill, J. (2021). Is the Emerging world Still Emerging?. Finance \& development 58, 02. New York: International $\begin{array}{lllll}\text { monetary } & \text { Fund. } & \text { Retrieved } & \text { January } & \text { 2022, }\end{array}$ https://www.elibrary.imf.org/view/journals/022/0058/002/022.0058.issue-002-en.xml

O'neill, J. (2001). Building better global economic BRICs. Global Economics Paper 66. New York: Goldman-Sachs.

Verma, S. (2021). Forecasting volatility of crude oil futures using a GARCH-RNN hybrid approach. Intelligent Systems in Accounting, Finance and Management, 28(2), 130-142.

Wilson, D., \& Purushothaman, R. (2003). Dreaming with BRICs: The path to 2050. Global economics paper, (99), 1.

\section{Notes}

Note 1. Wilson and Purushothaman (2003) predicted that the total nominal Gross Domestic Product (GDP) to hit US\$128 trillion in 2050 for the four BRIC countries, compared with US\$66 trillion for the G7 countries at the time.

Note 2. The vech (or vector-half) operator takes a symmetric $\mathrm{d} \times \mathrm{d}$ matrix and stacks the lower triangular half into a single vector of length $\mathrm{d}(\mathrm{d}+1) / 2$.

Note 3. While other the analysis of contagion during the US Subprime crisis used a "pre-crisis" and "crisis" periods, the author is of the opinion that the era preceding the Eurozone crisis was also marked by financial instability (driven mostly by the Subprime crisis) and is thus not a good representation of a tranquil period.

\section{Copyrights}

Copyright for this article is retained by the author(s), with first publication rights granted to the journal.

This is an open-access article distributed under the terms and conditions of the Creative Commons Attribution license (http://creativecommons.org/licenses/by/4.0/). 